\title{
EN BUSCA DE LA ESCUELA DEL SIGLO XXI: ¿PUEDE DARNOS LA PISTA LA ESCUELA NUEVA DE COLOMBIA?
}

\author{
Ernesto Schiefelbein, Rodrigo Vera, \\ Humberto Aranda, Zoila Vargas y \\ Víctor Corco.
}

\begin{abstract}
Resumen
Mejorar la calidad de la educación es ahora el principal desafío de los países de América Latina y del Caribe, pero puede ser una tarea muy difícil de llevar a cabo con éxito. Los indicadores de calidad de la educación básica han detectado la existencia de serios problemas de calidad en la mayoría de los sistemas educativos de América Latina. El que la educación sea de baja calidad merece una atención prioritaria de parte de los gobiernos, ya que tiene consecuencias, en muchas actividades y es especialmente crítica, ahora que el crecimiento económico y la democracia demandan personas con mejor formación. Sin embargo, muchos intentos por mejorarla no han tenido éxito. La escuela tradicional donde un profesor enseña a un alumno promedio (método frontal de enseñanza) enfrenta una cantidad de problemas y limita la posibilidad de ofrecer una educación de buena calidad adecuada a las exigencias del desarrollo económico. Sólo una revisión profunda de la educación básica, sobre la base de un nuevo modelo de escuela y métodos de enseñanza renovadas, permitiría lograr la calidad requerida para el siglo XXI.
\end{abstract}

Para redefinir la educación básica, para América Latina u otra región, se debe examinar la mejor experiencia disponible en la región o en el mundo. Una revisión detallada de los informes de evaluación de experiencias educativas y de los estudios preparados por agencias internacionales así como veinte años de visitas a escuelas en la mayoría de los países de América Latina, indican que la Escuela Nueva de Colombia (EN) es el modelo más adecuado para ser adoptado en otros países de la región. El programa EN evolucionó en los últimos veinte años desde un proyecto piloto para áreas rurales hasta un "conjunto modular de materiales", que funciona hoy día en 18.000 de las 24.000 escuelas públicas rurales de Colombia, incluyendo a todas las escuelas de uno o dos docentes. Este proceso ha demostrado que es posible implementar Escuela Nueva en Colombia y la posibilidad de adaptarla a otros países.

La parte I de este informe describe la situación de la educación primaria en América Latina para concluir que estos países deben buscar una alternativa, dado que la escuela tradicional enfrenta muchas dificultades para aumentar los actuales niveles de calidad. La parte II analiza los fundamentos implícitos del modelo EN; describe el desarrollo del modelo y su evaluación, e indica los elementos educativos utilizados por EN. La parte III presenta los principales aspectos de EN que los planificadores pueden implementar en otros países, las condiciones necesarias para su adaptación y concluye con algunos planteamientos de estrategias nacionales que se pueden desarrollar conjuntamente con la implementación de este modelo y las posibles opciones de perfeccionamiento del modelo EN.

\section{PRIMERA PARTE \\ ¿Están convencidos los países de América Latina y el Caribe que la calidad es el objetivo prioritario del desarrollo de la educación?}

Los educadores deben volver a examinar el pasado cada vez que nuevos hechos o nuevas interpretaciones de ellos generan otras metas para la educación o requieren su redefinición. La información reciente sobre matriculas por edades y nuevos indicadores ha sido utilizada para presentar una nueva visión sobre lo que se ha logrado en educación y para elaborar un nuevo marco para examinar los problemas por solucionar. 
En América Latina la mayoría de los niños de 10 años (93.2\%) están matriculados y permanecen en la escuela por 5 a 7 años; sin embargo, alrededor del $40 \%$ de los alumnos del primer grado son repitentes. La deserción escolar se inicia a los 12 años y alcanza a alrededor del 3\% del grupo de esa edad, pero luego aumenta al $9 \%$ a los 13 y 14 años de edad. Estas cifras indican que la necesidad de una mayor cobertura está superada y que ahora el problema se centra en la calidad. El análisis de la evolución y de los cambios en la política educativa en América Latina (así como en Colombia) demuestra que este es el momento preciso para concentrarse en todo lo relacionado con la calidad. Sin embargo, se debe llegar a un consenso sobre la clase de CALIDAD pertinente a la situación histórica y social de América Latina. La calidad, en este caso, está relacionada con cosas tan simples como la lectura, escritura y matemáticas elementales y en un aprendizaje que tenga relación con la vida cotidiana. Estas destrezas parecen demasiado elementales para muchos observadores (especialmente para aquellos que han enviado a sus hijos a buenos colegios públicos o privados), pero son muy difíciles de lograr en la escuela pública promedio que atiende a la mitad más pobre de la sociedad. A pesar de todas estas limitaciones se debe aceptar, como premisa, que los hijos de la pobreza son más capaces de lo que los educadores suponen (la evidencia en que se basa esta premisa se examinará en la Parte II).

Las tres secciones siguientes deberían dar a los planificadores educativos de América Latina los elementos de juicio para pensar sistemáticamente sobre calidad de la educación. La información reciente ha dejado en claro el papel clave de la calidad para elevar las tasas de escolarización (cobertura) y reducir el analfabetismo. Esta es la razón del porqué se le ha asignado una máxima prioridad a la calidad de la educación básica en la reunión regional de Ministros de Educación en Guatemala (1989), en la de Quito (1991) y en la Conferencia Mundial sobre Educación para Todos en Jomtien (1990).

\section{El acceso es casi universal, pero la calidad es aún deficiente}

La mitad de los niños, de un grupo de edad que haya pasado recientemente por la escuela, ingresa a la escuela a los seis años. Un tercio ingresa por primera vez con un año más. Menos del 10\% ingresa a los 8 y 9 años, y casi ninguno entra a una edad superior. En resumen, en América Latina el $93.2 \%$ de los niños de 10 años ingresa a la escuela (Tabla 1) y el resto, que no ingresa, está compuesto principalmente por aquellos que necesitan de cuidados especiales o son parte de una población rural extremadamente dispersa y aislada. El sistema debe hacer un esfuerzo final para dar oportunidades de educación a esos grupos dispersos y aislados; aun cuando, globalmente, el sistema educativo cuente con vacantes en las escuelas regulares para todos los niños que demandan educación. Hay suficientes profesores y aulas, pero su distribución y calidad debe ser mejorada. 
Tabla 1

Latinoamérica y el Caribe: población y tasas de Escolarización en educación básica por edades (1987)

\begin{tabular}{|c|c|c|c|c|c|c|c|}
\hline \multirow[b]{2}{*}{$\begin{array}{c}\text { Edad } \\
\text { (en años) }\end{array}$} & \multirow[b]{2}{*}{$\begin{array}{l}\text { Población } \\
\text { por edad }\end{array}$} & \multirow[b]{2}{*}{$\begin{array}{l}\text { Total } \\
\text { Región }\end{array}$} & \multicolumn{2}{|c|}{ Sur América } & \multirow{2}{*}{$\begin{array}{c}\text { Centro } \\
\text { América } \\
\text { Y } \\
\text { Panamá }\end{array}$} & \multirow{2}{*}{$\begin{array}{c}\text { Golfo } \\
\text { De } \\
\text { México }\end{array}$} & \multirow[b]{2}{*}{$\begin{array}{l}\text { Caribe } \\
\text { Inglés }\end{array}$} \\
\hline & & & Brasil $^{b}$ & $\begin{array}{l}\text { Resto } \\
\text { Países }\end{array}$ & & & \\
\hline 6 & 8.843 .010 & 55.0 & 21.2 & 68.3 & 42.3 & 90.9 & 90.2 \\
\hline 7 & 8.780 .656 & 86.1 & 73.6 & 92.2 & 80.8 & 99.2 & 87.0 \\
\hline 8 & 8.637 .546 & 91.6 & 83.9 & 94.1 & 85.1 & 100.0 & 96.9 \\
\hline 9 & 8.427 .466 & 93.3 & 88.0 & 95.6 & 84.0 & 100.0 & 98.4 \\
\hline 10 & 8.674 .819 & 84.4 & 54.1 & 91.2 & 84.7 & 100.0 & 100.0 \\
\hline 11 & 8.366 .927 & 87.7 & 81.6 & 93.0 & 79.9 & 92.3 & 89.4 \\
\hline 12 & 8.505 .755 & 82.4 & 77.0 & 85.7 & 76.8 & 86.7 & 95.9 \\
\hline 13 & 8.313 .207 & 71.1 & 72.4 & 78.2 & 65.1 & 76.2 & 92.4 \\
\hline 14 & 8.408 .966 & 64.9 & 59.5 & 70.1 & 53.0 & 67.8 & 85.5 \\
\hline 15 & 6.356 .853 & 45.2 & 49.3 & 47.0 & 39.3 & 27.6 & 32.0 \\
\hline \multicolumn{2}{|c|}{$\begin{array}{l}\text { Acceso a la escuela (mínimo } \\
\text { estimado) }\end{array}$} & 93.3 & 88.0 & 95.6 & 85.1 & 100.0 & 10.0 \\
\hline \multicolumn{2}{|c|}{$\begin{array}{c}\text { Edad en que comienza la } \\
\text { deserción }{ }^{d}\end{array}$} & 13 & $\begin{array}{c}10 y \\
13\end{array}$ & 10 & 14 & 14 & 15 \\
\hline
\end{tabular}

Fuentes:

Encuesta Siri - Orealc - Unesco: Celade. Estimación de población por edad simple, 1987. a. Incluye veinticinco países de la región. En el caso de tres países (Monserrat, San Kitts y Nevis y Trinidad y Tobago), sólo se consideró el grupo de 6 a 11 años.

b. 1986

c. El más alto porcentaje de escolarización en un grupo de edad en un año dado corresponde al acceso "mínimo" estimado para el grupo de esa edad, ya que parte de los alumnos que han estado matriculados en los años anteriores pudo haber desertado.

d. Edad en la cual desertó más del 15\% del acceso mínimo.

Ahora que el acceso es casi universal, los planificadores deben poner mayor cuidado en la permanencia de los matriculados (años de escolaridad), a su progreso hacia los grados superiores, a las oportunidades de estudio (tiempo para aprender) y, eventualmente, en el aprendizaje. En las siguientes secciones se examinarán los flujos de alumnos en los diversos grados de la escuela y, además, se estimarán los costos asociados al atraso o repitencia.

\section{Los alumnos permanecen matriculados varios años, pero sólo aprueban algunos grados}

La diferencia entre escolaridad y grados aprobados se genera por la cantidad de fracasos (o ineficiencia) del sistema o por la distancia entre las expectativas y la realidad. Los alumnos de América Latina se matriculan a una edad relativamente temprana $(86.1 \%$ a los 7 años) y la mayoría permanece matriculada por 6 o más años. La deserción es sólo de un $4 \% 9$ y 11 años, de un $5 \%$ a los 12 años, y la deserción masiva se inicia a los 13 ó 14 años (Tabla 1). El promedio de escolaridad es superior a los 6.7 años debido a la permanencia de los estudiantes mayores de 13 años. A pesar de esta alta escolaridad, el alumno medio aprueba menos de 5 grados (4.7 grados en los sistemas escolares de 6 
años de educación primaria). Por lo tanto, los grados aprobados corresponden a dos tercios del tiempo que permanecen en la escuela. Esta gran diferencia que se observa en América Latina (6.7 versus 4.7) está generada por las tasas de repetición y deserción. Como la tasa de deserción es relativamente baja se concluye que el porcentaje de repetición es una señal de la baja calidad de la educación impartida por la escuela y un indicador de la correspondiente pérdida económica.

Más del $40 \%$ de los alumnos de primer grado son repitentes. Hay demasiados alumnos con sobre-edad (un 50\%) matriculados en primer grado y como sólo el $8 \%$ se matricula tardíamente, la mayoría de ellos son repitentes (Tabla 2). Este alto nivel de repetición en primer grado explica que cerca de dos cohortes de edades estén matriculados en primer grado en cada año del período 1980 a 1987. Esta es otra forma de mirar el mismo problema: la mayoría de los niños (todos en algunos países), se matriculan y permanecen por mucho tiempo en los grados bajos (alrededor de la mitad de los alumnos pasa dos años en el primer grado) sin aprender el mínimo necesario para ser promovidos al grado superior.

Niveles similares de repitentes en el primer grado se han detectado para Sudamérica en las décadas del 70 y 80 usando modelos de simulación ${ }^{1}$. Los resultados de los modelos de simulación han sido comprobados, además, con los resultados de dos estudios de muestras de escuelas ${ }^{2}$ y con los de otros dos estudios de seguimiento de cohortes de edad ${ }^{3}$. En la Tabla 3 se presentan las estimaciones de tasas de repetición para el primer grado en el período 1970-1985. Mientras en 6 países se observa una reducción de la tasa de repetición, en dos se incrementa y, en otros dos, permanece casi al mismo nivel durante todo el período. El problema de la repetición debe ser afrontado permanentemente, en caso contrario las tasas vuelven a aumentar, como se constata en Chile (de 1983 a 1985) y en Uruguay (de 1981 a 1984).

Tabla 2: Educación primaria en Latinoamérica y el Caribe: Matrícula del primer curso, atrasados y repitentes (1987)

\begin{tabular}{|c|c|c|c|c|c|c|}
\hline \multirow[b]{2}{*}{ Variables } & \multicolumn{2}{|c|}{ Sur América } & \multirow{2}{*}{$\begin{array}{c}\text { Centro } \\
\text { América } \\
\text { Y Panamác }\end{array}$} & \multirow{2}{*}{$\begin{array}{l}\text { Golfo } \\
\text { De } \\
\text { México }^{d}\end{array}$} & \multirow[b]{2}{*}{$\begin{array}{l}\text { Caribe } \\
\text { Ingles }^{e}\end{array}$} & \multirow[b]{2}{*}{ Total } \\
\hline & Brasil $^{a}$ & $\begin{array}{l}\text { Otros } \\
\text { Países }^{\text {b }}\end{array}$ & & & & \\
\hline Matricula del 1er. grado & 7008806 & 2942806 & 863676 & 3570832 & 93718 & 14479912 \\
\hline Grado estándar & 7 & $6-7$ & $6-7$ & $6-7$ & $5-6$ & \\
\hline Alumno con 1-extra edad & 4081418 & 1227882 & 440401 & 1397995 & 20932 & 7168638 \\
\hline $\begin{array}{l}\text { Porcentaje de matricula } \\
\text { Máximo de alumnos no }\end{array}$ & 58.2 & 41.7 & 51.0 & 39.2 & 22.3 & \\
\hline Matriculados a los 7 años & 926360 & 159588 & 99452 & 18199 & 3365 & 1206964 \\
\hline Porcentaje de matricula & 13.2 & 5.4 & 11.5 & 0.5 & 3.6 & 8.3 \\
\hline Mínimo de repitentes & 3155068 & 1068294 & 340949 & 1379796 & 17567 & 5961674 \\
\hline $\begin{array}{l}\text { Tasa de repetición } \\
\text { (Estimación mínima) }\end{array}$ & 45.0 & 36.3 & 39.5 & 38.6 & 18.7 & 41.2 \\
\hline
\end{tabular}

Fuente: $\quad$ Unesco - OREALC. Situación Educativa de América Latina y el Caribe, 1980 1987, Santiago, Chile, 1990.

\footnotetext{
${ }^{1}$ E. Schiefelbein, 'Repetición, la última barrera para universalizar la educación primaria en América Latina”, Boletín del Proyecto Principal, No. 18, OREALC, abril de 1989, p. 19.

${ }^{2}$ E. Cuadra y G. Ewert, "Comparison of school records with parent's information on enrollment, repetition and drop out: a field study en Honduras", Project Bridges, Harvard University. julio de 1987; Wynn Crowder, "Gansu, Progress towards 9-year compulsory education" (borrador), Unicef, Beijing, abril, 1990.

${ }^{3}$ L. A. Alonso, La cohorte etaria: una vía alternativa para el estudio de la eficiencia interna en educación, División de Estadísticas y Sistemas, Ministerio de Educación Nacional, Bogotá, agosto de 1988; E. Schiefelbein. Repetición..., Op. cit., Tabla 1.
} 

a. 1986
b. Bolivia, Colombia, Chile, Uruguay y Venezuela.
c. Costa Rica, El Salvador, Honduras, Nicaragua y Panamá.
d. República Dominicana, Cuba y México.
e. Aruba, Dominica, Guyana, Jamaica, Santa Lucía y Suriname.

Tabla 3

Latinoamérica y el Caribe:

Tasas de repetición en diez países (1970-1985)

$\begin{array}{ccccccccccc}\text { AÑO } & \text { Argentina } & \text { Bolivia } & \text { Brasil } & \text { Colombia } & \text { Chile } & \text { Ecuador } & \text { Paraguay } & \text { Perú } & \text { Uruguay } & \text { Venezuela } \\ 1970 & 36.3 & - & - & - & - & 36.7 & - & - & - & - \\ 1971 & 33.6 & - & 55.8 & - & - & 36.7 & 40.1 & 41.8 & - & 15.6 \\ 1972 & 33.6 & 37.0 & 56.0 & 51.9 & 30.5 & 37.8 & 39.3 & 44.3 & 24.0 & 13.6 \\ 1973 & 35.7 & 3.8 & 54.4 & 50.5 & 32.6 & 34.4 & 37.2 & 41.2 & 20.3 & 20.8 \\ 1974 & 28.9 & 34.8 & 53.7 & 52.1 & 29.9 & 36.5 & 34.1 & 35.8 & 22.2 & 22.9 \\ 1975 & 28.8 & 35.0 & 54.6 & 54.0 & 27.0 & 35.7 & 39.3 & 33.5 & 23.7 & 26.9 \\ 1976 & 31.9 & 34.4 & 54.5 & 55.0 & 29.9 & 38.8 & 36.7 & 31.5 & 23.2 & 29.6 \\ 1977 & 30.5 & 33.2 & 57.5 & 57.3 & 30.0 & 35.7 & 37.8 & 37.7 & 19.8 & 27.0 \\ 1978 & 27.0 & 34.4 & 62.1 & 53.4 & 28.3 & 38.1 & 36.1 & 39.4 & 17.9 & 29.5 \\ 1979 & 27.7 & 33.7 & 57.4 & 45.8 & 25.1 & 40.0 & 35.2 & 43.3 & 17.9 & 29.8 \\ 1980 & 29.0 & 30.7 & 57.8 & 52.4 & 22.1 & 39.9 & 32.9 & 43.5 & 18.9 & 30.6 \\ 1981 & - & 32.8 & 57.9 & 42.4 & 13.8 & 39.1 & 32.6 & 45.8 & 17.6 & 30.1 \\ 1982 & - & 31.0 & 57.4 & 44.3 & 10.0 & 37.7 & 27.3 & 47.8 & 23.2 & 25.8 \\ 1983 & - & 34.2 & 57.6 & 42.0 & 10.0 & 36.2 & 29.1 & 45.2 & 21.7 & 26.5 \\ 1984 & - & 33.8 & 54.3 & 45.6 & 18.3 & - & 29.5 & 46.8 & 21.5 & 25.6 \\ 1985 & - & 33.5 & - & 35.7 & 14.0 & - & - & - & 19.1 & - \\ \text { Puntos } & & & & & & & & & & \end{array}$

Fuente: Resultado del Modelo Rates con datos del Banco de Datos de Unesco.

Nota: Las diferencias en las últimas cifras se calculan entre los valores del primer y último año.

\section{Un alto nivel de repitencia es una señal de que la calidad es baja}

El largo período de tiempo que emplea un repitente para pasar al grado siguiente puede ser interpretado de dos maneras muy distintas. Por una parte, la repetición ayudaría a elevar la calidad, en la medida que es un indicador de la flexibilidad con la cual el sistema escolar (el docente) responde a las diferencias en la capacidad de aprendizaje de los alumnos y a sus conocimientos previos. Gracias a esta atención flexible se aumentaría en un 50\% los recursos destinados al alumno medio de América Latina (a pesar de seguir utilizando los mismos métodos de enseñanza frontal), por lo tanto, muchos alumnos con bajo rendimiento finalmente logran cumplir objetivos demasiado ambiciosos para ser alcanzados en un solo año escolar. La repetición puede ser utilizada también como presión para que los alumnos eleven sus resultados en los exámenes nacionales, como se ha observado en los liceos de Colombia ${ }^{4}$.

Por otra parte, la repetición se puede interpretar como un indicador de la baja calidad de la enseñanza y, en la medida que la calidad se ha mantenido baja durante un largo periodo, la repetición indicaría que no se ha enfrentado adecuadamente este problema. Se puede suponer, entonces, que no se han conocido los resultados de experiencias

\footnotetext{
${ }^{4}$ G. Psacharopoulos y E. Vélez, Education quality and labor market outcomes evidence from Colombia, The World Bank. LATHR, enero, 1991, Table 1.
} 
exitosas para mejorarla o que existen problemas de gestión que no permiten poner en práctica modalidades de enseñanza que eleven la calidad y reduzcan los problemas de repetición. La utilización de recursos adicionales moderados, principalmente para textos y equipos mínimos, ha permitido mejorar la calidad de la educación de varios países con un monto adicional cercano al $5 \%$ del costo por estudiante (como ha ocurrido, por ejemplo, en la puesta en práctica de la Escuela Nueva, de Colombia, la Escuela para Aprender, de Chile, o los Instructores Comunitarios, de México).

Los alumnos de primer grado que al final del año escolar no pueden leer (deletrear) palabras sencillas, generalmente son reprobados y deben repetir el grado. La burocracia escolar parece suponer que una de las tareas importantes del docente es identificar aquellos niños que no están capacitados para aprender a de-codificar los sonidos de las letras, en vez de buscar la manera de solucionar los problemas de aprendizaje. Esta es una larga tradición y, por lo tanto, se genera una mayor tasa de repetición a medida que exista una menor calidad de la educación para ayudar al estudiante a adquirir las destrezas básicas de la lecto-escritura en el primer grado. Ciertamente se puede reducir la cantidad de repitentes con una ley de "promoción automática", pero el verdadero camino para enfrentar la repetición es mejorar la calidad de la educación (aunque dicha ley puede llamar la atención sobre el problema de la repetición y, de esa manera, provocar el interés de los docentes para mejorar su método de enseñanza).

La repetición parece estar ligada con la calidad en un circulo vicioso. Cuando los estudiantes repiten se produce una heterogeneidad de edades en sus cursos lo que hace muy difícil identificar al "alumno medio" que el profesor tiene que enseñar. El promedio de edad de los estudiantes de primer grado aumenta (en la actualidad el promedio de extraedad se acerca a un año de edad) y también la varianza de la distribución por edad. A mayor varianza en la edad corresponde una mayor cantidad de estudiantes que tendrán dificultades para seguir la enseñanza impartida por el profesor al "alumno medio" (los de las "colas" de la distribución normal del talento). Los malos estudiantes (en el lado izquierdo de la distribución) no pueden mantener el ritmo de la enseñanza por lo que terminan repitiendo grado, y los estudiantes más capaces, por aburrimiento, interrumpen el trabajo de la clase. Estudios hechos en México demuestran que los profesores escogen a quienes aprenderán (generalmente los niños de clase media tienen ventajas sobre los de la baja) y se concentran en esos niños.

En resumen, el alto nivel de repetición en primer grado sirve como indicador de la baja calidad de la educación y obliga a que casi la mitad de los estudiantes de ese grado dedique dos años de escolaridad para llegar a asociar sonido y letras (el primer paso formal del proceso de aprendizaje de la lectura). A pesar de que la relación entre repetición y baja calidad es menos evidente en los grados siguientes, los niveles de extraedad demuestran que los problemas son de una magnitud similar. En todo caso, una repetición "cero" no significa necesariamente que el sistema educativo sea de buena calidad.

\section{Los países están pagando muy caro el costo de la repetición}

Once millones de repitentes en la educación primaria en América del Sur ${ }^{5}$ y 17 millones en América Latina (un $30 \%$ de la matrícula) permiten estimar que el costo de la baja calidad, solamente en términos de repetición se acerca a los 3.000 millones de dólares por año. Esta cifra se estima, fácilmente, ya que el promedio de costo por estudiante en la

\footnotetext{
${ }^{5}$ E. Schiefelbein, Repetición..., op. cit., p. 19.

Digitalizado por RED ACADEMICA
} 
educación primaria es más de US\$150. La sociedad global obtendría grandes beneficios si invirtiera dinero para reducir la repetición. Aun pequeños logros en la calidad, que generen una reducción de la repetición, lograrían probablemente que cualquier esfuerzo masivo para aumentar la calidad de la educación fuera costo/eficiente.

El modelo Escuela Nueva (EN) que se ha puesto en práctica en Colombia y que se comenta más adelante, aumenta los costos recurrentes unitarios en menos de $10 \% \mathrm{y}$, por lo tanto, es muy conveniente estudiar sus características e impactos. La implementación de EN en Colombia logró una fuerte reducción de la repetición conjuntamente con un incremento de los rendimientos académicos. Eso se logró aun cuando "la parte del gasto correspondiente a la educación primaria colombiana a partir de 1975 bajó continuamente, a pesar que la asignación de recursos aumentó algo en términos reales"6.

\section{Cada familia también comparte el costo de la baja calidad}

La repetición significa permanecer mayor tiempo en la escuela con los consecuentes gastos adicionales relacionados con la participación en la escuela y puede ser aceptada solamente si no hay otro modo razonable para cumplir con los requisitos de aprendizaje necesarios para pasar de grado (es el caso de los estudiantes de bajo rendimiento que necesitan mayor cantidad de tiempo). Pero una mejor calidad de la educación puede permitir al repitente alcanzar mejores logros educativos en ese tiempo escolar adicional $o$ acortar el tiempo necesario para obtener un nivel dado de educación. Por ejemplo, cuando los alumnos utilizan textos de autoaprendizaje (educación personalizada) los maestros pueden dedicar más tiempo al trabajo con los estudiantes de bajo rendimiento.

\section{Elementos que hacen particularmente difícil la tarea innovadora}

La escuela tradicional de América Latina no ofrece la calidad de educación que se requiere en los 90s. En esta sección se analizan los límites para mejorar la calidad dentro del modelo de escuela tradicional y se concluye que la escuela tradicional permitiría introducir muy pocos progresos en la medida que los países deben elevar la calidad bajo severas restricciones económicas. Cada innovación dentro del modelo tradicional requiere de más insumos de muy diversos tipos, a menos que cambie el tipo de escuela y se produzcan drásticos cambios en la asignación de recursos. En resumen, seria necesario encontrar un modelo alternativo para aumentar la calidad de la educación al nivel que se requiere para el siglo XXI. La posibilidad que la Escuela Nueva pueda contribuir a identificar ese modelo se investiga en la Parte II.

En este capítulo se analiza el impacto de los insumos y procesos sobre el aprendizaje actual de los niños de nivel socioeconómico bajo ${ }^{7}$. La pertinencia de las conclusiones depende de una identificación realista de las escuelas tradicionales que se analicen. Hay dos opciones: (i) escoger la escuela que corresponda al promedio nacional, y (ii) seleccionar la escuela que atienda a alumnos del nivel socioeconómico más bajo de la población. Dado que el problema de la repetición afecta principalmente a la mitad más pobre de la población, el análisis se centrará en las escuelas públicas que atienden niños de las zonas urbano-marginales y rurales $^{8}$.

\footnotetext{
${ }^{6}$ Ministerio de Educación, Análisis del sector educativo, con énfasis en sus aspectos administrativos y financieros. Bogotá, 1988.

${ }^{7}$ Finn Ch., "The biggest reform of all", Kappan, Vol. 71, No. 8, abril de 1990, pp. 584-592.

${ }^{8}$ CPEIP, "Resultados por estructuras en las asignaturas de matemática del 40 . año de enseñanza básica en 1982", Serie Estudios, No. 120, julio de 1984. 
El análisis se centrará en el proceso diario que se lleva a cabo en la escuela, tomando en cuenta el contexto donde está localizada, es decir, incluyendo la familia, la comunidad y las condiciones políticas y socioeconómicas que influyen en el proceso educativo ${ }^{9}$. El elemento clave para ser analizado es el comportamiento de los maestros en la escuela tradicional y su habilidad para acumular el conocimiento pedagógico así como el contexto que condiciona su comportamiento. Las características de los profesores de escuelas tradicionales se comentan en los párrafos iniciales y el ambiente del aula y el proceso de aprendizaje se describen en el resto del capítulo. En cada caso se trata de identificar las oportunidades que existen para mejorar la calidad de la educación y los logros académicos de los alumnos. De los análisis llevados a cabo en este capítulo un planificador podría sacar como conclusión que la combinación de las características del profesor de escuela típica con la invitación a aprender memorizando como loro, que hace la mayoría de los textos, crean una barrera insuperable para mejorar la educación en la escuela tradicional.

\section{Muy pocos maestros han participado en un proceso de aprendizaje activo}

La mayoría de los maestros de América Latina pasaron a lo menos doce años (y algunos hasta 18 años) sentados muy quietos en sus escritorios o bancos, mientras su profesor les hablaba o escribía en el pizarrón, describiendo hechos, dando definiciones y afirmaciones que tuvieron que memorizar. Cerca del $80 \%$ de los maestros ha asistido a escuelas normales $o$ universidades pedagógicas donde se les instruyó en el uso de metodologías de enseñanza activa y memorizaron los pasos para su práctica o las características de los modelos pedagógicos disponibles. Muy pocos docentes han tomado parte en un proceso pedagógico de aprendizaje activo.

En resumen, muy pocos docentes de América Latina pueden (o podrían) enseñar empleando un método activo, porque este método no fue usado durante su formación docente, ni tampoco durante su educación primaria y secundaria. Este es un serio obstáculo para los planificadores educacionales y las alternativas se comentarán en la Parte $\|^{10}$.

\section{Los bajos salarios y falta de selección al ingreso limitan la innovación}

Existe una amplia gama de docentes, desde los que cuentan con una alta calificación profesional hasta los "cuidadores de niños" que tienen una formación deficiente y poca motivación. Hay muchos tipos de maestros, pero se puede apostar que el profesor de una escuela tradicional va a ser muy diferente de los que lean este informe y ganarán un salario mucho más bajo. El que lee este informe es, probablemente, un profesional de gran talento, que ha innovado, que es capaz de motivar a los estudiantes (o al personal) y guiarlos hacia una indagación personal que dé origen a un conocimiento sólido. Cada lector potencial de este informe, en América Latina, habrá sido seleccionado entre más de 1.000 maestros que trabajan en el sistema educativo de la región y debe controlar su tendencia a suponer que su capacidad está cerca del promedio.

\footnotetext{
${ }^{9}$ Una descripción excelente del impacto en el rendimiento escolar del ambiente de las familias pobres aparece en Maria Luisa Vial. "Desarrollo y resultados de una experiencia educacional no-convencional" CPU, Documento de Trabajo No. 47/90, Santiago de Chile, noviembre de 1990.

${ }^{10}$ Algunos de estos enfoques y el aprendizaje como búsqueda a las diferencias individuales se comentan en D. Tanner y L. Tanner, History of the School Curriculum, MacMillan, 1989 p. 400. 
Supongamos que los maestros altamente calificados constituyen entre un 10 y un $20 \%$ del total de la región ${ }^{11}$. Estos maestros pueden reproducir la habilidad de Freinet para conseguir que sus estudiantes editen sus propios textos de estudio. Este tipo de maestro puede generar experiencias de aprendizaje extraordinarias con solo utilizar una docena de piedrecillas recogidas en el camino hacia la escuela. Hay un segundo grupo de maestros que recibió capacitación, cumplió con los requisitos para obtener un título de maestro, pero carece de la creatividad, persistencia y experiencia que posee el primer grupo. Para este segundo grupo de maestros el "pasar la materia" o enseñar un cierto currículo es la principal meta de su labor profesional. Este segundo grupo de maestros puede constituir un 30 a un $40 \%$ del total de docentes de un país.

Finalmente, hay un grupo de maestros que no tienen formación profesional o se matricularon en pedagogía porque no fueron aceptados en otras carreras ${ }^{12}$. Un 40 a un $50 \%$ de los maestros de América Latina se incluyen en este tercer grupo y probablemente ganan la mitad del salado que el segundo grupo y un cuarto que los del primer grupo ${ }^{13}$. Además de sus bajos salarios, estos maestros deben viajar generalmente largas distancias todos los días, trabajar con pocos materiales de enseñanza, hacer frente a un grupo donde prevalecen las enfermedades y aún la violencia. Sin supervisión (o una recompensa profesional por su labor de enseñar) este tercer grupo de maestros no dedica mucho tiempo extra para preparar su próxima hora de clase y muchos no tienen talento para crear nuevas formas de enseñanza. La mayoría de los maestros de una escuela tradicional pertenece a este tercer grupo, hay varios del segundo, pero son muy escasos los del primer grupo. Los mejores profesores son rápidamente detectados por los colegios privados o escuelas públicas que pueden pagar altos salarios y los contrata para mejorar su calidad; esas escuelas suelen atender a alumnos de clase alta. En resumen, la escuela tradicional no puede contratar maestros altamente calificados y le será difícil implementar innovaciones para mejorar la calidad de su educación. Si bien una buena capacitación y experiencia no significa necesariamente una enseñanza de buena calidad, la falta de capacitación suele estar muy unida con bajos logros escolares.

\section{Se espera demasiado de la actuación del maestro}

Aunque se espera que los docentes creen situaciones de aprendizaje maravillosas cada vez que dictan una clase, ellos no cuentan con una Riente de los conocimientos adquiridos con la cual desarrollar una buena enseñanza ${ }^{14}$. Cada maestro debe crear cada clase improvisando, sobre la base de principios o guías muy generales (se suele usar antiguas notas personales). No existe una descripción de la mejor práctica efectuada por buenos especialistas, como en el caso de la cirugía ${ }^{15}$. Los docentes son como un

\footnotetext{
${ }^{11}$ El predominio de mujeres y las características sociales son variables importantes en los procesos de selección y promoción, pero no se exploran aquí porque no afectan el funcionamiento de EN.

12 Los mejores alumnos suelen postularse a carreras que están ligadas con trabajos que tienen buenos salarios. Los salarios de los profesores están bajo el promedio y, por ende, educación sólo atrae a alumnos con notas relativamente bajas.

${ }^{13}$ Las diferencias de salarios son importantes porque la sociedad asigna salarios bajos a los profesores. En EE.UU. el salario del profesor está muy cerca del salario de los plomeros y más bajo que el de las enfermeras. Stanley M. Elam, "The 22nd annual Gallup Poll of the public attitudes toward thé public schools", Kappan, Vol. 72, No.1, septiembre de 1990, p. 48.

${ }^{14}$ Los académicos de América Latina pueden obtener información de los 18.000 informes disponibles en el banco de datos de Reduc, pero los maestros de escuela no tienen acceso a las experiencias y métodos más adecuados para enseñar un determinado tema.

${ }^{15}$ En unas 2.000 páginas cualquier manual de cirugía ofrece descripciones detalladas de los procedimientos quirúrgicos que se deben emplear para resolver un problema y sugerencias de las opciones existentes en cada etapa. Como editan suplementos periódicos con nuevas técnicas, un tercio del libro puede cambiar cada cinco años.
} 
violinista, al que se le pidiera que "creara" un concierto tan magistral como el Concierto para Violín de Beethoven en cada nueva presentación, en vez de pedirle que realice una "interpretación" magistral de esa partitura. Se desea que el maestro intervenga entre el texto de estudio y el estudiante que lo use y por eso se diseñan textos que motiven al profesor en vez de ofrecer instrucciones claras al alumno. El texto actual sólo busca inspirar al profesor, tal como la melodía propuesta inspira a tocar a un jazzista. De ahí que hay muchos maestros motivados tratando de desarrollar nuevas experiencias de aprendizaje. pero que no utilizan las experiencias ya disponibles para ofrecer un buen aprendizaje. Desafortunadamente el texto clásico suele ser demasiado extenso, aburrido, lleno de datos insulsos, carente de desafíos, desprovisto de substancia y. prácticamente, ineficaz con relación al desarrollo del razonamiento. En muchas salas de clases la Ciencia todavía se enseña como un conjunto de hechos y principios que debe ser memorizado, y los niños se consideran como pizarras en blanco sobre las cuales los docentes deben escribir $^{16}$. Dado que los textos de estudio tienen un lugar importante en el método con que se desarrolla la clase tradicional, al determinar qué se estudia y la forma de enseñarlo, se concluye que hay que readecuarlos o lo que es más difícil, formar un nuevo tipo de docentes.

Al mirar el problema, desde el punto de vista de los planificadores, se identifican opciones claras. Como la readecuación de la actitud de los docentes es una tarea a largo plazo hay que producir una generación de textos de estudio completamente nueva, con instrucciones paso a paso. Esos libros deben cumplir varios criterios. Por ejemplo, si las tareas tienen una "respuesta correcta", el grupo descubrirá rápidamente que un solo alumno puede hacer el trabajo mejor y más rápido que el grupo. En tal caso, habrá muy poca interacción, y las investigaciones muestran que la interacción es una importante fuente de aprendizaje en el trabajo del grupo ${ }^{17}$. En resumen, se requiere editar una nueva generación de textos de estudio que tengan instrucciones "paso a paso" para que los alumnos realicen la experiencia de aprendizaje (como si fueran enseñados por el mejor especialista de ese tema). Esta estrategia implica un proceso de largo plazo (que involucra a muchos especialistas del país y extranjeros) que debería iniciarse lo antes posible y que debería ser mejorada gradualmente en las futuras ediciones.

\section{Se espera que los maestros donen demasiado tiempo extra}

Cualquier reforma del currículo se debe planificar sobre una base realista en cuanto al tiempo libre que un maestro, de acuerdo con el nivel de motivación, pueda entregar para implementar esa reforma. Esa estimación se debe elaborar a partir de un análisis del nivel de formación profesional, del tiempo que destinan a preparar las clases del día siguiente, el tiempo que usan para la disciplina de la clase; el tiempo disponible en la escuela (pero no en la clase), y el que destina en la casa, para evaluar pruebas o comentar trabajos escritos. Una apreciación realista de estas actividades daría un perfil de la forma en que operan la escuela y el maestro (tomando en cuenta la cantidad de tiempo requerido por un maestro, con la formación media existente en cada tipo de escuela, para producir experiencias de aprendizaje significativas). Es probable que el perfil resultante indique que se dedica poco tiempo extra por encima de la jornada regular. Esa conclusión será, probablemente, muy diferente de lo que hacían en sus escuelas los maestros que leen este informe (o la manera como suelen enseñar, para aquellos planificadores que son o han sido maestros). En resumen, una propuesta de reforma podrá tener éxito sólo si no se

\footnotetext{
16 Problemas similares existen en los países desarrollados. 13. Watson y R. Konicek, "Teaching for conceptual change: confronting children's experience", Kappan, Vol. 71, No. 9, mayo de 1990, p. 681.

${ }^{17}$ E. Cohen, "Continuing to cooperate: prerequisites for persistence", Kappan, Vol. 71, No. 2. octubre de 1990, pp. 134-138.
} 
demanda tiempo adicional al maestro (o al menos muy poco) y si los cambios propuestos pueden ser expresados en material escrito con instrucciones paso a paso que los niños puedan seguir (ayudados por el profesor).

\section{Es muy poco el tiempo que se le otorga al alumno para que aprenda}

El alumno medio dispone de poco tiempo para aprender en la escuela tradicional porque el año escolar es muy corto y son pocas las horas de clase por día, por las ausencias de los actores y el mal uso del tiempo de los maestros. El número real de días de clases del año escolar en una escuela tradicional no excede de 160 y el horario diario varía entre tres y cinco horas ${ }^{18}$. El tiempo de enseñanza/aprendizaje se reduce debido a que los actores faltan a la escuela durante el año. Los alumnos, principalmente los del área rural, abandonan la escuela durante parte del año y algunos maestros hacen uso de permisos por enfermedad. Hay ausencias de los alumnos en el tiempo de cosecha, carga/descarga de camiones o buques, o ventas semanales o mensuales en ferias de productos agrícolas o comerciales. Y el poco tiempo que queda para el aprendizaje a veces se usa muy mal. Un estudio venezolano sobre la administración de las clases encontró que sólo el $40 \%$ del tiempo destinado a impartir clases era usado efectivamente para la enseñanza. La mitad del tiempo se pierde en ocio y la otra en cambio de actividades ${ }^{19}$. En Chile entre el 50 y el $64 \%$ del tiempo de los docentes se destina a la enseñanza y un 22 a $29 \%$ adicional a controlar la disciplina ${ }^{20}$. Casos similares se han detectado en otros países de América Latina. Esta mala utilización del tiempo está vinculada a la falta de una tradición de trabajo tutorial o individualizada en la región. En resumen, no existen incentivos para que la escuela alcance el mínimo de tiempo destinado para aprender y, menos aún, para asegurar que ese tiempo se emplee realmente en las tareas de aprendizaje; la técnica frontal de enseñanza ("prédica") no permite el trabajo individual (o en grupo) de los alumnos en tareas de aprendizaje y la falta de motivación aumenta el desorden, que hacen perder al maestro un valioso tiempo de clases en tratar de imponer disciplina.

\section{Son muy pocas las clases que motivan realmente a los estudiantes para aprender}

La heterogeneidad de edades y el que los alumnos no tengan oportunidades para tomar decisiones sobre lo que deben aprender reducen el interés por aprender y, además, el tiempo que se dedica a aprenden La heterogeneidad de edades característica para América Latina y el Caribe (por ejemplo, escolares de 6 a 13 años de edad en primer grado) limita el interés de los alumnos "promedio" en lo que el maestro trata de enseñar, ya que su única opción es poner o no poner atención a las instrucciones del docente. La menor atención significa un aumento del nivel de indisciplina, por lo tanto, se reduce aún más la atención que se da a los profesores. No es fácil romper este circulo vicioso generado por las edades heterogéneas. Al menos no es posible hacerlo en el modelo de escuela tradicional. Probablemente la mitad de las escuelas latinoamericanas esté alcanzando el nivel máximo de calidad posible para el método de enseñanza frontal al

\footnotetext{
${ }^{18}$ Cuando se descuentan los días feriados y vacaciones Colombia alcanza a 170 días de clases de 4 a 5 horas por día, con un total de 680 horas por año, en comparación con 1.100 en USA, 1.300 a 1.600 en Europa y aún más en Japón. J. B. Toro, Primero mi primaria: para triunfar; Fundación Social, Bogotá, 1988.

${ }_{19}$ Nacarid Rodríguez, La educación básica en Venezuela, Escuela de Educación, Universidad Central, Caracas, 1990.

20 Dos sesiones, con un tiempo total de 180 minutos en una escuela pobre que opera un currículo personalizado. J. Filp, C. Cardemil et al. "Control social, disciplina y cambios: estudio de las prácticas pedagógicas en una escuela básica popular", Documento de Trabajo del Cide, 1987 (RAE 4553). y. Espínola informa que los maestros solo dedican el $72.5 \%$ del tiempo de clase dentro de la sala de clases, en "Evaluación del sistema de mercado como estrategia para mejorar la calidad de la enseñanza básica subvencionada", Documento de Discusión del Cide, No. 5, 1990, p. 42.
} 
alumno "promedio" 21 . Muchos maestros se esfuerzan para mejorar el rendimiento del alumno medio hasta el máximo posible, pero a costa de sacrificar trabajos más interesantes para los alumnos más brillantes y de sentenciar a los menos capacitados a repetir el grado porque no pueden seguir el ritmo del estudiante medio ${ }^{22}$. En todo caso, a pesar del esfuerzo de los maestros, el resultado es bajo, tanto en términos de los altos índices de repetición como en términos del bajo nivel de lectura comentado al principio de este informe. En resumen, más tiempo del maestro, más opciones de los alumnos para aumentar su motivación y una instrucción personalizada, son las herramientas que permiten incrementar el tiempo dedicado al trabajo, elevar el logro del estudiante y, eventualmente, reducir la heterogeneidad de edades. Sin embargo, cualquiera de estas tres actividades es difícil de implementar en una escuela tradicional que utilice el método de enseñanza frontal.

\section{Desvinculación del aprendizaje tradicional con la vida diaria}

No existen suficientes mecanismos para evaluar si el conocimiento adquirido por los alumnos es realmente útil en la vida diaria, ni se prepara a los alumnos para ser más selectivos en relación con lo que ellos desean aprender. Los alumnos de sectores pobres están en doble desventaja; primero, porque su patrón de comportamiento, uso del lenguaje y valores no concuerdan con aquellos requeridos en la escuela tradicional; segundo, porque los docentes no sacan provecho de las posibilidades que ellos poseen. A pesar de que la vida diaria está presente en los colegios de clase alta, está ausente en la formación de la escuela tradicional o está en conflicto con la cultura de la escuela ${ }^{23}$. Las experiencias de aprendizaje de los alumnos de clase alta se relacionan con lo que ellos ven en excursiones, viajes durante sus vacaciones, revistas, videos y museos y con las conversaciones con sus padres, profesionales amigos de la familia y padres de sus compañeros de clase. Los alumnos de sectores pobres también tienen acceso a personas muy interesantes y a un contexto con múltiples estímulos, pero las experiencias de aprendizaje de las escuelas no aprovechan toda la riqueza de esas realidades. La escuela tradicional no invita al estudiante a identificar en su contexto los objetos locales y actividades relacionadas con el trabajo, transporte, salud, alimentación, producción, historia, geografía, cuentos, fábulas, adivinanzas, canciones de cuna, vegetales, animales, minerales y todos los demás temas incluidos en el currículo nacional que pueden ser observados en su propio medio. En resumen, el escaso vínculo del conocimiento adquirido en la escuela con la vida diaria de los estudiantes menos favorecidos puede crear un ciclo de fracaso y desesperación que culmina en la repetición $y$, eventualmente, en el abandono. Por lo tanto, a menos que se encuentre un instrumento para mejorar la relación con la realidad, que incluya la experiencia local en el aprendizaje diario, los niños menos favorecidos estarán en desventaja y será difícil elevar la calidad de la educación.

\section{Los alumnos de escuelas tradicionales no tienen oportunidades para pensar}

\footnotetext{
${ }^{21}$ Sólo el $30 \%$ de los maestros de primaría no tiene un certificado o título profesional, pero un $10 \%$ ha obtenido un certificado participando en cursos en servicio. Hay suficientes maestros preparados. pero los salarios no son un incentivo para atraer maestros a zonas aisladas o peligrosas. E. Schiefelbein, J.C. Tedesco et al, "La enseñanza básica y el analfabetismo en LAC: 1980-1987", Boletín del Proyecto Principal, No. 20, diciembre de 1989.

${ }^{22} \mathrm{Se}$ han experimentado con éxito las clases de recuperación con un maestro adicional, monitores comentarios y madres, pero estas alternativas no evitan el que se produzcan nuevos problemas. El costo unitario tiende a subir substancialmente cuando se usan profesores adicionales.
}

\footnotetext{
${ }^{23}$ M.L. Vial. "Desarrollo y resultados de una experiencia educacional no convencional", CPU. Documento de Trabajo, No. 47/90. Santiago de Chile, noviembre de 1990. 
Investigaciones basadas en la observación de las clases impartidas en las escuelas tradicionales sugieren que los alumnos tienen pocas oportunidades para desarrollar un pensamiento autónomo ${ }^{24}$. El pensamiento propio ocurre cuando el alumno hace preguntas originales, responde a preguntas interesantes, escribe ensayos y toma decisiones sobre las experiencias de aprendizajes ${ }^{25}$, pero es muy raro que sucedan estas actividades en una escuela tradicional. Los maestros tienden a aceptar las preguntas relacionadas solamente con el tema tratado (generalmente aburrido) y la pregunta original es desviada o postergada. Muchas de las preguntas de los maestros sólo piden una repetición carente de sentido y no impulsan el desarrollo del pensamiento. No hay incentivo para que los maestros soliciten composiciones libres, debido a que posteriormente deben evaluarlas y comentarlas en su tiempo libre, puesto que la organización de la escuela tradicional no permite hacer ese trabajo en la jornada diaria. Por lo tanto, la escritura libre se minimiza y la mayoría de los alumnos solamente escribe unas dos páginas de ensayos al año, como ha sido detectado en investigaciones y en visitas a las escuelas, (generalmente se solicita a los estudiantes escribir una página sobre las vacaciones o alguna efeméride nacional). Finalmente, el método de enseñanza frontal, basado en la copia y memorización, no permite al alumno tomar decisión alguna. En resumen, a menos que el tiempo que los maestros dedican a dictar clases, o a copiar en el pizarrón, sea drásticamente reducido, no habrá oportunidades para que los alumnos utilicen su capacidad de pensar. Para que los maestros reduzcan la "transmisión" de conocimientos es necesario introducir un conjunto de métodos de enseñanza diferente, centrados en textos de autoaprendizaje que liberen al maestro de dar las instrucciones e información rutinarias.

\section{Los alumnos de sectores más pobres no tienen acceso a computadores}

Los países de América Latina han importado computadores personales para que los alumnos de los niveles sociales alto y medio estudien, tanto en la escuela como en el hogar, (en algunos países burlando restricciones aduaneras), pero solamente Costa Rica ha extendido el acceso a los computadores en forma masiva ${ }^{26}$. Chile importó 150.000 computadores personales en el período 1985-1990 principalmente para los niveles socioeconómicos altos ${ }^{27}$. A pesar de que no se conoce con precisión cuál es el papel del computador en el proceso de aprendizaje $e^{28}$, es posible apostar que aumentaría la brecha en los niveles de aprendizaje entre aquellos que tienen y los que no tienen acceso a los computadores. La mayoría de los planificadores que lean este informe harán lo posible para dar a sus niños la oportunidad de trabajar con computadores. Pero los niños de familias con pocos recursos no tienen acceso al computador (proveer un computador personal por cada 10 estudiantes representa ahora un costo de alrededor de US\$40 por estudiante y si se supone una duración promedio de seis años representaría alrededor de US\$7 por alumno/año para ser financiado con préstamos internacionales). En resumen, las escuelas tradicionales pueden ser dotadas con computadores personales para

\footnotetext{
${ }^{24}$ Johanna Filp, El primer año de escuela en Chile, Documento de trabajo del Cide, 1988 (RAE 5145). Ver también, Gabriela López, "The organization of teachers' practices embedded en Chilean cultural forms", Tesis Universidad de Toronto, 1988; J. Assael y otras, Alumnos, padres y maestros: la representación de la escuela. PIIE, Universidad de Humanismo Cristiano, septiembre de 1989.

${ }^{25}$ Decisiones que impliquen algo más que "prestar o no prestar atención al profesor".

${ }^{26} 40 \%$ de los alumnos de educación primaria de Costa Rica tienen acceso a una o dos horas de trabajo en un computador y se ha programado completar la cobertura en 1991.

${ }_{27}$ Se importan unos 20,000 a 30,000 computadores por año. La mayor parte de ellos corresponde a equipos pequeños tipo Atari.

${ }^{28}$ Hay criticas sobre los efectos de los programas de Enseñanza Asistida por Computador, pero hay sugerencias para reestructurarlos y hacerlos más efectivos. R. E. Slavin "IBM's writing to read: it is right for reading", Kappan, Vol. 72, No. 3, noviembre de 1990, pp. 214-2 16; B. Collis, Computers, currículum and wholeclass instruction, Wadsworth, 1988, pp.412.
} 
empezar a familiarizar-se a esta nueva tecnología. Las escuelas podrían reducir la desigualdad usando cajas de cartón para practicar procesos de clasificación, pero la actual planta física de la escuela tradicional (y el papel del maestro) no es suficientemente flexible para esta adaptación.

\section{Objetivos realistas en cuanto a la calidad de la educación en América Latina y el Caribe}

Muchos desearían que en la escuela se enseñaran múltiples materias y habilidades. Sin embargo, el uso de la expresión "enseñar" no debería permitirse si el alumno "promedio" no logra el objetivo. No es correcto decir "yo enseño a mi hijo a nadar, pero cada vez que se mete al agua se va al fondo" ${ }^{29}$. Sólo se puede decir que la educación tuvo éxito si el alumno alcanza el saber definido como meta. Entonces, para definir lo que debería enseñarse, necesitamos saber qué es lo que se aprende realmente en las aulas en América Latina y el Caribe. La presencia de alumnos y de un adulto, junto a escritorios, textos y pizarrón no significa necesariamente que exista un proceso educativo (y menos que sea bueno). La alta tasa de repetición y los bajos puntajes en los estudios internacionales sobre rendimiento sugieren que el resultado de los procesos llevados a cabo en las aulas en las zonas urbano-marginales y rurales es de baja calidad.

El desafío, entonces, consiste en rechazar las ilusiones y definir aquellas materias y destrezas que es posible enseñar realmente en la escuela y que los alumnos pueden aprender y aplicar más tarde en la vida real (aunque sean muy pocas). Sin embargo, hay un continuo flujo de mensajes que sugieren que: (i) el concepto de calidad debe ser amplio y abarcar varios campos; y (ii) las demandas futuras tienden a exigir un mayor nivel de calidad de la educación. Por ejemplo, el presidente Pérez expuso que la escuela debe "hacer de la ciencia parte constituyente de la cultura del ciudadano" 30 . El hombre de negocios americano dice que se requiere una sólida calidad de la educación básica para competir en la economía del mercado mundial ${ }^{31}$, mientras que los expertos japoneses desearían mejorar la creatividad en sus escuelas. Muchos países están preocupados por la calidad de sus escuelas ${ }^{32}$. Por otro lado, diferentes economistas de América Latina y el Caribe han concordado recientemente que se necesita una mejor educación para lograr un crecimiento económico sostenido ${ }^{33}$.

Si se acepta la premisa de que existe un "bajo nivel actual de la calidad de la educación", entonces basta tener unos pocos indicadores para medir los niveles actuales de calidad en vez de investigar en muchas dimensiones. Por ejemplo, el bajo nivel de lectura que sugiere el alto porcentaje de repitentes en primer grado, algunas pruebas nacionales y observaciones de clases en muchas escuelas de América Latina y del Caribe demuestran consistentemente que la mayoría de los estudiantes de quinto y sexto grados tienen dificultades para comprender lo que leen. El rendimiento en las áreas rurales es, por supuesto, menor que el promedio nacional ${ }^{34}$. Los alumnos menos favorecidos tienen

\footnotetext{
${ }^{29}$ Chester E. Finn, "The biggest reform of all”, Kappan. Vol. 71, Ño. 8, abril de 1990, p. 586.

${ }^{30}$ Carlos A. Pérez, Discurso pronunciado por el Presidente de Venezuela en el acto de instalación de la III Conferencia General de la Academia de Ciencias del Tercer Mundo, Caracas, octubre 15 de 1990.

${ }^{31}$ Fortune, "If you think education is expensive try ignorance", New York Times, octubre 25 de 1988, p. A32.

32 "The best schools en the world", en Newsweek, diciembre 2 de 1991. pp. 49-60.

${ }^{33}$ CEPAL, Transformación productiva con equidad. LC/G. 1601-P. Santiago de Chile, marzo de 1990.

${ }^{34}$ Un estudio en el sur de Chile detectó un $66 \%$ de alumnos urbanos y un $83 \%$ de alumnos rurales con problemas para comprender lo que leían. A. Repossi. J. Araneda et al, "Nivel de comprensión lectora en escolares rurales de la Comuna de Valdivia y algunos factores condicionantes", Estudios Pedagógicos, No. 15, 1989, pp. 43-56.
} 
un alto índice de repetición y muy bajos puntajes en las pruebas estándar ${ }^{35}$. La mitad de los adultos matriculados en campañas de alfabetización ya asistió a la escuela en su niñez ${ }^{36}$.

Estos indicadores demuestran que hay que considerar cuatro necesidades básicas de aprendizaje antes de intentar metas más complejas de calidad: /comprensión de lectura, comunicación escrita, valoración de la ciudadanía y manejo de una metodología para aprender a partir de la realidad en que se vive. Es fácil agregar otros objetivos pero, como se comentó anteriormente, será difícil satisfacer plenamente aun la primera de estas cuatro metas.

\section{Los niños deben aprender a leer (comprendiendo lo que leen)}

Aprender a leer (comprendiendo bien lo que se lee) es la piedra angular de la calidad de la educación. A pesar de ser el primer paso hacia la autonomía, generalmente los planificadores del currículo suponen que es fácil de adquirir esta habilidad porque sus propios niños suelen estar leyendo antes de entrar a la enseñanza básica. Los planificadores del currículo forman parte del mayor nivel intelectual de cada país y tienden a olvidar los problemas de los niños menos favorecidos. Estos últimos no aprenderán a leer (comprendiendo lo que leen) porque asistieron a una escuela tradicional de América Latina y del Caribe, es decir, escuelas que: (i) dirigen su enseñanza al alumno promedio y se olvidan de aquellos que no son capaces de aprender el currículo ii) se guían por el currículo nacional sin usar ejemplos de la vida diaria del lugar para generar un aprendizaje interesante y efectivo (iii) no tienen tiempo adicional para atender a los alumnos de bajo rendimiento ya que todo el tiempo se dedica al alumno promedio (iv) no estimulan una manera propia de razonar, y $(v)$ no poseen computadores o equipos como los utilizados como estímulo adicional para los alumnos de nivel socioeconómico alto (lo que eleva eventualmente el nivel de exigencia del currículo nacional, debido a que esos estudiantes tienen la posibilidad de mejorar su desempeño, y tienden a generar altos niveles de repetición).

\section{Los niños deben aprender a comunicarse en forma escrita}

Una sociedad moderna tiende a operar mediante mensajes escritos. La habilidad para seguir instrucciones y enviar mensajes va un paso más allá de la lectura y la escritura. Un conductor de camión debe llenar formularios y llevar una contabilidad simple. El trabajo en el sector productivo de servicios requiere un buen manejo de la escritura. En el sector informal es necesario conocer algo de contabilidad. Los mensajes telefónicos deben ser dejados por escrito. El manejo de un teléfono moderno requiere de un manual de 150 más páginas y también la capacidad de discar mensajes complejos. Las máquinas automáticas de venta, transporte y teléfonos públicos operan con instrucciones $y$ mensajes escritos. En resumen, los niños deben aprender la aptitud de comunicarse por escrito para vivir en esta sociedad. De hecho los dos primeros objetivos básicos están ligados en términos de recibir, seguir y dar instrucciones. Por ejemplo, el uso del transporte público obliga a dar o seguir instrucciones y aún los juguetes y los equipos domésticos vienen listos para armar siguiendo largas y a veces complejas instrucciones.

\footnotetext{
${ }^{35}$ Los alumnos chilenos de familias en el quintil de ingreso alto logran un $80 \%$ de respuestas correctas y los del quintil más bajo obtienen un $40 \%$ (sin corregir por la posibilidad de elegir entre cuatro alternativas).

${ }^{36}$ Rosa Maria Torres, Evaluación de La Campaña de Alfabetización del Ecuador Ministerio de Educación, Quito. 1990.
} 
Los valores se aprenden imitando modelos, mediante experiencias que generan satisfacciones u observando personas competentes o destacadas. Para que los niños sean agentes de la democracia deben practicar los valores democráticos y ser influidos por líderes de los alumnos en vez de memorizar hechos sobre las instituciones democráticas, elecciones, derechos y responsabilidades. El "gobierno de la escuela" (consejo de alumnos) es un mecanismo valioso donde los niños pueden apreciar las ventajas y desventajas de una vida cívica y democrática. Participando ellos aprenden a tolerar las diferencias y a tratar de comprender el punto de vista de los otros participantes. La habilidad de proponer acciones concertadas es, también, otra consecuencia de la participación de los comités de alumnos.

\section{Los niños deben ser capaces de aprender observando la realidad}

Los niños deben tener la oportunidad de observar la realidad por si mismos, de describir con precisión y de reflexionar sistemáticamente sobre lo observado. Experiencias educativas que incluyan estas tres dimensiones deberían desarrollar la habilidad de pensar por sí mismo en vez de acatar creencias convencionales. Describir es el primer paso en el enfoque científico de los problemas y un requisito para comprender la ciencia y su uso en la vida diaria. Una vez que estos fundamentos estén bien enraizados es posible desarrollar altos niveles de comprensión, complementando los conocimientos con ejercicios en analogías, diferencias, inconsistencias, búsqueda de información, mayor desarrollo de la comunicación con los demás y la voluntad de aprender de los errores cometidos.

\section{Estos objetivos, a pesar de ser modestos, necesitan un nuevo modelo de escuela}

A pesar de los significativos avances del sistema educativo de América Latina, en los últimos quince años, la población rural y urbano-marginal sólo puede mejorar la calidad de su educación primaria si se implementa un nuevo tipo de escuela. Las mayores deficiencias del sistema educativo rural tradicional incluyen: métodos pasivos, un currículo que no toma en cuenta la riqueza del contexto; falta de formación especial de los maestros en técnicas multigrado a pesar que la mayoría de ellos debe dar clase a varios grados en una misma sala de clases; falta de materiales educativos para apoyar el proceso de aprendizaje, tanto para maestros, como para alumnos; rigidez en el calendario y horario; y falta de participación de los padres.

Los países están afrontando dos serias restricciones: (i) maestros sin formación para ofrecer una enseñanza activa, que no pueden ser reemplazados por maestros calificados; y (ii) falta de tiempo extra para que los maestros puedan atender a los alumnos que necesiten más tiempo para aprender. El caso de EN de Colombia (ver Parte II) puede ayudar a los planificadores para diseñar un nuevo modelo que eleve la calidad de la educación a pesar de estas dos desventajas.

\section{SEGUNDA PARTE El modelo escuela nueva (EN): Intentos de descripción}

¿Qué es EN? EN se puede definir como un conjunto modular de mate-dales educativos, de bajo costo, que los maestros y alumnos usan con facilidad y que permitió mejorar la calidad de la educación básica rural en Colombia, a pesar de ser implementado de 
manera masiva (siguiendo instrucciones detalladas para el proceso de capacitaciónimplementación).

La mejor forma de apreciar el método EN consiste en visitar una escuela que lo aplique. Sin embargo, EN se puede describir también a partir de cuatro perspectivas diferentes. EN es lo que el visitante observa en el trabajo cotidiano de una escuela que aplique ese método; es una serie de insumos utilizados sistemáticamente en un proceso de enseñanza; es el conjunto de principios subyacentes que son parte del proceso con que opera EN; es el resultado de un largo desarrollo en el tiempo (dada la complejidad de la serie de innovaciones estratégicas integradas en el paquete, su desarrollo demoró 15 años) y, finalmente, EN es un conjunto de resultados. La descripción de la visita se presenta en esta introducción y cada uno de los otros cuatro enfoques se presenta en los siguientes capítulos. Los educadores que lean este informe pueden reflexionar sobre las relaciones entre estos cuatro enfoques.

\section{Reportaje de una visita a cualquiera de las 20.000 EN colombianas}

Las otras cuatro perspectivas de EN están comentadas en los siguientes capítulos. El Capítulo 4 describe la infraestructura y los insumos -incluyendo la capacitación que acompaña y sigue la implementación del modelo- El Capítulo 5 trata de los principios que explican POR QUÉ funciona y contiene breves comentarios sobre el CÓMO funciona. El capítulo 6 describe el desarrollo del modelo EN y la expansión de la cobertura. La evaluación de la experiencia, las cifras de los costos y las implicaciones para otros países se discuten en el capítulo 7 junto con otras estrategias nacionales para mejorar la calidad de la educación que pueden llevarse a cabo si se implementa un modelo como el de EN.

\section{Se usa una docena de insumos básicos para poner en práctica $E N^{37}$}

El lector debe tener presente que EN requiere insumos específicos porque el proceso de aprendizaje depende del modo en que se utilizan esos insumos. Los insumos básicos se pueden organizar en cuatro grupos: (i) una escuela de demostración que pruebe que el modelo funciona; (ii) unos cinco materiales de educación de bajo costo; (iii) un programa de capacitación muy buen definido, para cambiar las actitudes de los maestros y (iv) un estilo de administración de la escuela basado en cinco actividades. En la primera sección se analizan las características y funciones de las escuelas de demostración.

Los cinco materiales de educación utilizados en el proceso son: guías para alumnos y pautas para los educadores; una pequeña biblioteca de 100 libros; tres rincones de aprendizaje y una pequeña repisa suponiendo que se dispone de mesas planas y sillas para los alumnos así como escritorio y silla para el maestro; y construcción del plano de la zona que atiende la escuela.

La capacitación está concebida como un proceso continuo durante el cual se usan diversos modelos educativos y donde hay algunos individuos que mantienen el contacto con las escuelas y universidades. La capacitación incluye: visita a escuelas modelos; un nuevo rol del maestro; tres seminarios de capacitación de una semana cada uno y participación semanal en un microcentro (taller).

\footnotetext{
${ }^{37}$ Esta sección está basada en V. Colbert, c. Chiappe y J. Arboleda, The New School Programme: More and better primary education for children en rural areas, Ministerio de Educación/Unicef. Bogotá, septiembre de 1990. 
El nuevo estilo administrativo de la escuela está basado en cinco actividades distintas: funcionamiento de un gobierno estudiantil; uso del contexto local, de grupos de trabajo y de tutores que individualicen la atención. El costo real del paquete es ligeramente más alto que el costo de la escuela tradicional (alrededor de 5 a $10 \%$ más caro, tal como se examina en el capítulo 7) que corresponde a la mayor capacitación y a la supervisión de, por lo menos, las escuelas modelos. En el caso colombiano, estos costos adicionales han sido asumidos con la ayuda de la Unicef mientras que la terminación, reparación y mantenimiento de las escuelas, así como el equipamiento, manuales y costos relacionados con la capacitación han sido financiados a través de un préstamo del Banco Mundial.

Una descripción detallada del proceso de implementación (instrucciones para cada etapa de la puesta en práctica) supera el alcance de este informe, pero se comentarán cada uno de los insumos centrales. El orden de presentación de los insumos trata de aproximarse, hasta donde es posible, la secuencia del proceso de implementación de EN en una escuela.

\section{Los maestros comprueban en escuelas de demostración que EN es efectiva}

El punto de partida para transformar una escuela tradicional en una de tipo EN, es que los maestros visiten una escuela de demostración o laboratorio ${ }^{38}$. Los maestros quedan listos para cambiar sus comportamientos después de visitar una buena escuela de demostración, de verificar cómo se resuelven los problemas concretos y de discutir con maestros experimentados acerca de la práctica educativa ${ }^{39}$. Visitar una escuela que funciona con el sistema EN basta para interesar a un maestro en experimentar el método ${ }^{40}$.

La única forma de quedar convencido que EN realmente funciona (aun en escuelas que operan con poca (o mala) infraestructura) es visitar una escuela modelo. Es demasiado difícil aceptar que están sucediendo muchas cosas positivas en las EN y aún más difícil convencerse de que no es tan complicado implementar dos docenas de actividades diferentes. Si los docentes se convencen de que todos estos logros se pueden realizar con menos esfuerzo de su parte ( $y$ con una mayor satisfacción profesional) que en una escuela tradicional estarán, entonces, dispuestos a cambiar sus métodos de enseñanza (a pesar de haber estado inmersos en los métodos tradicionales por tantos años). Las escuelas de demostración son un elemento central del cambio de estrategia ${ }^{41}$. Estas son las escuelas en las cuales los maestros expertos practican, los maestros principiantes aprenden las técnicas y los investigadores las estudian. Las escuelas de demostración tienden a estimular el trabajo en equipo, la colaboración, la toma de riesgos y la experimentación; y valoran, tanto la individualidad, como al grupo. Estas escuelas tienen que llegar a ser uno de los eslabones de la educación pública en las que los

\footnotetext{
${ }^{38}$ No existe una manera única de iniciar la construcción de una nueva visión para una escuela, pero la experiencia demuestra que el empezar por visitar una escuela de demostración es una manera muy efectiva de hacerlo.

${ }^{39}$ Las escuelas de demostración tienen una infraestructura y un personal docente promedios. Sólo el método de enseñanza es diferente.

40 «Exploración de campo". K.H. Flechsing y E. Schiefelbein en "Catálogo de modelos didácticos" [Versión 1985 - 1986], Documento de Trabajos, No.4, Cide, Santiago de Chile, 1985 (ver nota a pie de página No. 38).

${ }^{41}$ Los maestros han aprendido en forma pasiva durante los 6 a 9 años de educación básica, seguido con el mismo modelo expositorio durante los 4 a 6 años de escuela secundaria y en las escuelas normales y colegios de enseñanza, y han escuchado pasivamente que la enseñanza debe ser activa. Los maestros deben, entonces, observar un modelo activo que tiene éxito para desear probarlo.
} 
miembros de las facultades universitarias, maestros expertos, maestros principiantes y alumnos K-12 (de todos niveles) se juntan para mejorar la calidad de la educación.

\section{Textos de autoaprendizaje con instrucciones detalladas}

Los alumnos de primer grado de EN pasan la mayoría de su tiempo aprendiendo a leer y escribir (tal como en cualquiera escuela tradicional), pero a partir del segundo grado, los alumnos pasan la mayor parte de su tiempo trabajando con materiales de autoaprendizaje que estimulan: aprender de manera activa, tomar decisiones, en habilidades intelectuales, las discusiones y toma de decisiones en grupo, observación y sistematización de elementos existentes en el medio local ${ }^{42}$. Los textos de autoaprendizaje preparados para cuatro asignaturas específicas (idioma, matemáticas, ciencia y estudios sociales) pueden ser aplicados fácilmente por maestros con poca calificación porque incluyen instrucciones detalladas para los alumnos ${ }^{43}$. Sin embargo, la utilización de estos textos se optimiza mucho cuando los maneja un maestro bien calificado. La secuencia de objetivos es consistente con el currículo nacional, pero se asegura que los alumnos usen actividades pertinentes al medio rural y a la comunidad (siempre existe la posibilidad de complementar el texto nacional con un suplemento para cada región). Los textos de autoaprendizaje se proporcionan gratuitamente a las escuelas, pero en cantidades limitadas (cuatro para cada niño), después de haberlos probado cuidadosamente (y reeditado) en grupos piloto. Un tercio de la escuela reportó que se requería de un mayor número de textos.

Además de los textos de autoaprendizaje de los estudiantes (Guías de Aprendizaje) con sus actividades de ejercicios graduados y secuenciados, se dispone del material de la biblioteca de aula para las actividades de libre elección. Los profesores cuentan con una Guía de Enseñanza, muy práctica, complementada por material normativo y de recuperación, así como con instrucciones y sugerencias para ser usadas en los microcentros, es decir, las reuniones periódicas con colegas. Los textos de autoaprendizaje de los alumnos ayudan al profesor a atender varios grupos al mismo tiempo, que es el requisito para dar instrucción personalizada. Los textos también pueden indicar a los alumnos que pongan por escrito recetas de cocina locales, para comparar las diferentes versiones y aun para experimentar preparando en la escuela alguna receta con ayuda de madres y padres. De esta manera, el contexto local se integra a la escuela, la comunidad también participa y los maestros no tienen que gastar mucho tiempo cada día en preparar la próxima clase, pero está listo para ayudar a los alumnos a proponerse (y lograr) metas personales. El énfasis en el uso del texto está basado en la experiencia de campo y en los resultados de investigaciones que muestran que el uso de textos es la variable (cuantificable) que tiene mayor impacto en la excelencia académica. El mejorar la calidad de los textos ayudará, también, a mejorar la calidad de la educación ${ }^{44}$.

Los rincones de aprendizaje permiten realizar actividades diferentes en forma simultánea, dentro de la sala de clases

\footnotetext{
${ }^{42}$ Flechsing y Schiefelbein, "Método de tarea (Dalton Plan)", Catálogo..., Op cit.

${ }^{43}$ E. Schiefelbein y P. Farrés, "Evaluación formativa de libros de texto de educación primaria", Revista Latinoamericana de Estudios Educativos, Vol. XXI, No. 2, 1991.

${ }^{44}$ S. Heyneman, D. Jamison y X. Montenegro, "Textbooks en the Philippines. Evaluation of the pedagogical impact of a nationwide investment", en Educational Evaiuation and Policy Anaiysís, 6 (2), 1984.

Digitalizado por RED ACADEMICA
} 
Los rincones o centros de aprendizaje son espacios organizados en cuatro áreas curriculares básicas: matemáticas, ciencias naturales, estudios sociales y lenguaje ${ }^{45}$. Cada área contiene objetos construidos por los alumnos, o aportados por la comunidad siguiendo las instrucciones de los textos y las sugerencias de los profesores. Por ejemplo, el rincón de la ciencia incluye una mesa de arena. El texto de autoaprendizaje dirige a los alumnos para que observen y manejen objetos concretos (informes, dibujos, u objetos) estimulando así su desarrollo cognitivo. Uno de los rincones de aprendizaje incluye unas cinco a seis cajas de cartón pequeñas (con una base suficientemente grande como para poner hojas sueltas de cuaderno). Los alumnos pueden clasificar en las cajas sus informes, poemas, recetas, mapas, dibujos, adivinanzas, o ensayos y más adelante pueden reclasificar ese material de acuerdo con un nuevo criterio (tal como se clasificaban las tarjetas perforadas en las máquinas clasificadoras de IBM). Los alumnos pueden aprender así los procesos básicos que están detrás de la operación de los computadores y estar listos para usar computadores tan pronto como las escuelas tradicionales reciban el equipo necesario.

\section{Bibliotecas de aula (sala de clases) para los alumnos avanzados}

La Escuela Nueva está lista para canalizar la energía de aquellos alumnos que alcanzan los rendimientos del currículo nacional antes de lo previsto. Muchos alumnos son capaces de llegar a ese nivel rápidamente y después comienzan a pedir nuevas actividades de aprendizaje. Los maestros deben estar listos para ofrecerles un desafío adicional en la pequeña biblioteca de aula. Una biblioteca de 100 libros bien seleccionados (que incluye diccionarios, textos por asignaturas, literatura infantil y libros sobre desarrollo de la comunidad) es un recurso clave para el curso. (Un $94 \%$ de la muestra de escuelas de 1987 las tenía). La biblioteca se usa como un complemento al texto de autoaprendizaje, que permite a los niños aprender sobre nuevas áreas (o para encontrar el punto de partida para un nuevo módulo) y ofrece un espacio de actividad para los que aprenden más rápido. Los niños aprenden a organizar su biblioteca a través del Comité de biblioteca del gobierno escolarv Los miembros del Comité están a cargo de prestar y cuidar los libros.

\section{Las sillas y las mesas deben permitir el trabajo de grupos de aprendizaje}

Aun cuando parezca que las mesas son menos importantes que otros insumos, el trabajo de grupo depende (en cierta medida) en la disponibilidad de mesas planas que puedan juntarse para permitir el trabajo de un grupo de cuatro o cinco alumnos. Las mesas de forma trapezoidal son excelentes. Los bancos tradicionales clavados en el piso limitan la posibilidad de trabajar en grupo. El único mueble adicional que se requiere en Escuela Nueva es un estante para guardar los textos de autoaprendizaje. Se recomienda que, al menos, el estante sea proporcionado por la comunidad de manera que, tanto los maestros como la comunidad se preparen (anímicamente) para implementar la Escuela Nueva.

Preparar los mapas de la zona que atiende la escuela (o el curso) y usar información de la comunidad

Se ha desarrollado una relación estrecha entre la Escuela Nueva y la comunidad a través de una secuencia de actividades muy simples que son parte del currículo. Como parte del

\footnotetext{
${ }^{45}$ Los "rincones de aprendizaje" son un tipo del modelo de "exhibición de feria educativa" en que los alumnos interactúan con los objetos disponibles, aunque también tienen elementos de los "gabinetes de aprendizaje”. Ver Flechsing and Schiefelbein, Catálogo..., Op cit.
} 
primer taller los profesores reciben guías para que los alumnos preparen el mapa de la comunidad (una representación del vecindario o zona que atiende la escuela) donde se colocan los nombres de la familia de cada uno de los estudiantes. Como resultado de ese proceso cada uno de los estudiantes llega a ser un experto en diseño de mapas y en su significado. El gran mapa se coloca en un lugar visible cerca de la entrada principal de la escuela. Los padres encuentran sus nombres en el mapa y se sienten que son una parte importante de la escuela. Es un detalle, pero uno muy importante. Junto con entregar guías para esta actividad, se entregan guías para explicar a la comunidad lo que significa implementar Escuela Nueva para los niños y la comunidad, y para mejorar el espacio físico. Estas guías se discuten con los profesores que desean implementar Escuela Nueva, durante la semana que dura el primer seminario de entrenamiento. Más adelante los alumnos le preguntan a sus padres y amigos información que luego será usada como experiencias de aprendizaje. Por ejemplo, se lleva un registro de información familiar ( $91 \%$ de las escuelas lo tienen), un calendario de eventos agrícolas (un $60.5 \%$ de las escuelas) y varias monografías sociales y culturales (un $77.2 \%$ de las escuelas). Los textos de autoaprendizaje pueden ser adaptados, tanto para la región, como para la localidad (sí es económicamente factible) para incluir materiales de enseñanza más pertinentes.

\section{El nuevo rol del profesor es el rol que los profesores desean desempeñar}

El rol tradicional de los profesores como la "fuente" del conocimiento ha sido redefinido drásticamente en la Escuela Nueva en términos de "asistencia para una indagación personal", pero los maestros que desean comenzar a implementar Escuela Nueva tienen oportunidad de participar en el esfuerzo de reestructurar su rol. De ahí que los maestros de Escuela Nueva no están especializados en dar instrucciones rutinarias en alta voz, ni tampoco en custodiar alumnos o mantenerlos callados ${ }^{46}$ por lo que renuncian a la protección de que gozan los maestros que trabajan en escuelas manejadas por reglas en las cuales las interacciones son totalmente en términos de tareas y resultados.

Después de una breve estadía en una escuela de demostración y de participar en el segundo taller de entrenamiento, donde aprenden a usar el texto de autoaprendizaje, los maestros de la Escuela Nueva empiezan a usar gran parte de su tiempo como facilitadores: (i) revisandoo si las instrucciones escritas han sido comprendidas; (ii) motivando a los estudiantes para que hagan trabajo extra; (iii) atendiendo a los estudiantes con problemas (para sacar partido de la habilidad peculiar que suelen poseer aun los estudiantes con más dificultades), (iv) guiando a los estudiantes para que aprendan a través de la interacción en grupo y aumentar la autodeterminación, y (v) mostrando a los estudiantes conductas apropiadas para manejar distintos tipos de miedos $^{47}$. Este nuevo rol (que se refuerza en los microcentros y al ver el éxito de sus alumnos) es clave para reducir los serios problemas de aprendizaje que enfrentan los alumnos de escuelas tradicionales. Los alumnos que no comprenden las instrucciones escritas en los módulos suelen ser ayudados por sus compañeros de grupo; y se reduce

\footnotetext{
${ }^{46}$ Dado que el alumno participa de manera involuntaria (como en las prisiones y hospitales), los profesores que tienen una orientación de "cuidadores" consideran la indisciplina como una afrenta personal de alumnos que deben ser castigados. Ver W. Hoy y A. Woolfolk, "Socialization of Student teachers", American Educational Research Journal, Vol. 27, No. 2, pp. 279-300.

${ }^{47}$ Los niños tienen miedos y ansiedades que limitan un desarrollo académico y social. N. King y T. Ollendick. "Children's anxiety and phobic disorders en school settings: classification, assessment, and intervention issues", Review of Educational Research, Vol. 59, No. 4, invierno de 1989, pp. 431-470. Ver además F. Guida, S. Arancibia y E. Merino, "Un estudio del dominio afectivo en educación", Serie Estudios No.132, CPEIP, Santiago de Chile, 1984.
}

Digitalizado por RED ACADEMICA 
el efecto perverso de las bajas expectativas de los profesores para con los estudiantes con desventajas, porque los estudiantes van siguiendo instrucciones específicas y objetivos comunes (aunque los medios puedan ser diferentes) ${ }^{48}$.

Da la sensación que los maestros avanzan a través de etapas a medida que abandonan las prácticas de la enseñanza tradicional y adoptan la forma en que se trabaja en la Escuela Nueva. En cada etapa la sensación de eficiencia de los profesores parece aumentar y (de acuerdo con los resultados de investigaciones) los rendimientos de los alumnos también aumentan ${ }^{49}$. El nuevo rol supone que existen textos de lectura para los alumnos de primer grado y textos de autoaprendizaje para los alumnos de segundo a quinto grados. De ahí que el profesor de multigrados (cuando trabaja con alumnos de primer grado) concentra la mitad de su tiempo en enseñar a los nuevos a leer y escribir y supervigila el avance del trabajo personal de los alumnos de los grados siguientes. Las instrucciones de los textos hacen que los alumnos se relacionen (observen, pregunten, consulten, comparen) con situaciones de la vida diaria y que lleven a cabo experimentos. Por ejemplo, les piden llevar piedrecillas o semillas a la sala de clases para clasificarlas, para describir qué es lo que están haciendo, para que compartan sus ensayos escritos y, de cuando en cuando, para solicitar retroalimentación de parte del maestro.

\section{Entrenar maestros en usar los textos y los "trucos" de la Escuela Nueva}

El entrenamiento de los maestros consiste en aprender CÓMO usar los materiales de autoaprendizaje y demás insumos y términos (trucos). Los maestros aprenden "haciendo Escuela Nueva" en una secuencia interrelacionada de entrenamiento en talleres e implementación que toma lugar durante el primer año (en vez de aprender los principios subyacentes y esperar que creen sus propios módulos y materiales). Tres seminarios (talleres) programados paso-a-paso, de una semana de trabajo, preparan a los maestros en cómo empezar a trabajar con la comunidad, usar los textos, organizar el espacio de la sala de clases, instalar y operar el gobierno estudiantil, usar la biblioteca de aula como un poderoso recurso adicional y, más adelante, a ser capaz de introducir todos los cambios que crea necesarios para atender a cada niño y a cada localidad o vecindario ${ }^{50}$. Cada uno de los tres talleres de entrenamiento de una semana está organizado por la unidad regional encargada del entrenamiento (descentralizado), con períodos intermedios de práctica (con alguna supervisión limitada cuando es posible). Los funcionarios de la unidad administrativa ya han sido entrenados en visitas a (y trabajos en) las escuelas en demostración, y participado en un "taller para agentes administrativos de la región" que consistió, también, en aprender el cómo implementar Escuela Nueva.

En el primer taller cada profesor: visita una escuela de demostración; aprende algunas técnicas para operar el gobierno estudiantil (Consejo Escolar); reflexiona sobre la disposición física de la sala de clases y la organización de los Rincones de Aprendizaje (Centros de Actividades); y participa en discusiones de grupo que ayudan a los maestros a trabajar, más tarde, con pequeños grupos en sus propias salas de clases. Los maestros

\footnotetext{
${ }^{48}$ Hay maestros que interpretan el lenguaje popular como errores y otros que tienen bajas expectativas en relación con la mala apariencia de los alumnos, por lo que les exigen menos y no permiten que alcancen niveles adecuados de desarrollo académico. Ver Michael 8. Knapp and Patrick M. Shields, "Reconceiving academic instruction for the children of poverty", Kappan, Vol. 71, No. 10, junio de 1990, p. 753.

49 P. Ashton, "Motivation and the teachers' sense of efficacy" en C. Ames y R. Ames (eds.), Research on motivation en education, Academic Press, 1985, pp. 141-174.

${ }^{50}$ Vicky Colbert y Oscar Mogollón, Hacia la Escuela Nueva, Ministerio de Educación Nacional, 1977, 7a. edición.
} 
usan Guías de formación (Manual del Profesor) para desarrollar cinco unidades: la Escuela Nueva y la Comunidad; la construcción del local escolar; los rincones de aprendizaje (centros de enseñanza); y otros materiales para el proceso de aprendizaje en la sala de clases; el gobierno escolar; y los métodos de trabajo en grupo. Los maestros abordan el proceso de aprendizaje a través de la práctica y experimentan, ellos mismos, el aprendizaje activo. Tan pronto los maestros regresan a sus escuelas comienzan a adaptar la escuela para el trabajo de Escuela Nueva, movilizan a la comunidad para mejorar la escuela, y experimentan con el gobierno escolar. Los maestros alientan a los niños y a la comunidad para recoger información útil acerca de la comunidad y llegar a entender su propia historia. El mapa del vecindario y una visita de los padres a una escuela de Escuela Nueva son herramientas adicionales para lograr el apoyo de la comunidad. En ese momento, se puede (debe) cambiar las bancas por mesas individuales o construir los estantes para los rincones de aprendizaje. El primer taller de una semana de entrenamiento en servicio para profesores y supervisores constituye un pre-requisito indispensable para que la escuela quede incluida en el Programa de Escuela Nueva y se complementa durante el resto del primer año con otros dos talleres de una semana.

El segundo taller tiene lugar cuando la escuela ya está adaptada para el trabajo en pequeños grupos, se ha elegido el primer gobierno escolar, y la comunidad está informada acerca de la Escuela Nueva (dos o tres meses después del primer taller). En una semana los profesores aprenden a usar correctamente los textos de autoaprendizaje, practican el enseñar en multigrado (como instrucción de grupo en diferentes grados), discuten la promoción flexible (trabajo por módulos), y se sienten capaces de introducir tantas innovaciones como ellos se sientan cómodos. Los maestros trabajan con el texto de autoaprendizaje tal como los niños trabajaran con ellos (aprendizaje a través de la práctica). Los maestros ensayan con los textos de autoaprendizaje (Guías) aceptan que hay muchas respuestas posibles (no hay UNA SOLA respuesta correcta) y aprenden cómo planear el uso de módulos (unidades temáticas). Al final del taller los maestros reciben los sets de materiales. Los sets corresponden a uno o varios grados dependiendo de cómo está estructurada la escuela. Las escuelas pequeñas con un profesor de multigrado reciben tres sets de cuatro áreas básicas para cada uno de los cinco grados; las escuelas con un grado por sala (graduados) reciben 15 sets de cuatro áreas básicas para el grado en el cual el profesor enseña.

En el tercer taller los maestros aprenden a organizar y usar la biblioteca de aula, los mapas, los posters, la promoción flexible y a reforzar la habilidad para trabajar con varios niveles (o grados) al mismo tiempo. En este último taller revisan los mecanismos previos y avanzan en el uso de las técnicas de evaluación y desarrollan su capacidad de resolver problemas imprevistos. Al final del tercer taller cada profesor recibe los 100 libros de la biblioteca de aula. Este entrenamiento básico ha sido capaz de motivar y capacitar a los profesores, aun cuando el entrenamiento previo al ingreso al sistema EN tendría que ser tomado en cuenta en otros casos.

Microcentros para mantener el interés y para resolver los problemas y dudas que surgen en la implementación

Los microcentros reducen la incertidumbre y los temores de los maestros durante la implementación de nuevos métodos de enseñanza. Después de cada taller se invita a los maestros a reunirse una vez al mes en una escuela cercana (los microcentros suelen operar en escuelas de demostración cuando están disponibles) para analizar problemas y discutir resultados. El contar los logros, compartir las dudas y pensar en voz alta permite 
avanzar hacia soluciones específicas y experimentarlas ${ }^{51}$. Los microcentros dan un marco de referencia para reestructurar los esfuerzos de las escuelas ${ }^{52}$. Después del período de entrenamiento los profesores continúan asistiendo a los microcentros para unirse a otros profesores que enfrentan desafíos similares, intercambian ideas, prácticas, experiencias e impresiones, intentan nuevos enfoques y forman alianzas con otras instituciones, de manera que puedan explorar otras alternativas posibles. Las experiencias en discusiones de grupo también ayudan al maestro a trabajar más adelante con pequeños grupos en su propia sala de clases. Sin embargo, existen algunos problemas para operar los microcentros. Por ejemplo, los participantes tienden a identificar a un líder en el grupo y se crea dependencia con respecto a ese líder, a menos que se implemente una coordinación rotativa. Se están buscando maneras de conectar los microcentros con Universidades y empresas privadas para agregar elementos dinámicos al proceso y para unir a practicantes e investigadores de una manera flexible ${ }^{53}$. En general, los microcentros representan una oportunidad para combatir la rutina y el aburrimiento: se autocrítica las prácticas de los profesores, se intercambian las experiencias: se discuten las soluciones a nuevos problemas y, eventualmente, se prueban y evalúan, al mismo tiempo que se llevan a cabo actividades de capacitación ${ }^{54}$. Se deben asegurar visitas periódicas de supervisores para mantener la motivación y para identificar las experiencias que deberían ser compartidas con grupos de profesores que se reúnen en otros microcentros. En los microcentros se alienta a los participantes a escribir las estrategias de aprendizajes que tengan éxito y los resultados de los experimentos a fin de ir acumulando el conocimiento práctico sobre enseñanza.

\section{Usar contenidos locales y acumular el conocimiento pedagógico}

Cada día de clases los alumnos de Escuela Nueva identifican (siguiendo instrucciones de los módulos) elementos locales que sirvan para las experiencias de aprendizaje y acumulan elementos culturales e información económica representativa de la región. Esto es consistente con las investigaciones que concluyen: "cuanto más significativa sea una actividad, más profunda o más elaborada sea la manera en que se procesa, cuanto más relacionada con el contexto y más enraizada en la cultura y contexto y más relacionada con el conocimiento previo, más fácil será entenderla, aprenderla y recordarla'55. Los textos de autoaprendizaje guían a cada alumno en la identificación de ejemplos y elementos culturales que puedan ser usados en cada experiencia de aprendizaje y en la recolección de los materiales locales que conviene acumular en los rincones de aprendizaje. La tradición oral es transcrita y clasificada en: proverbios, canciones de cuna y folclóricas, adivinanzas, juegos, mitos, leyendas, cuentos, recetas, o descripciones de la vida social en las décadas pasadas ${ }^{56}$. También se puede describir y clasificar para un

51 Corresponde al modelo Taller educativo en la clasificación (le los modelos de aprendizaje. Podría evolucionar hacia el modelo Red de usuarios o de educación mutua' cuando se cuente con mayores facilidades de comunicación. Ver Flechsing and Schiefelbein. Op. cit.

52 O. Mogollón. El Microcentro y el proceso de educación permanente en Escuela Nueva Ministerio de Educación, 1980. Ver también Programa Escuela Nueva, los microcentros rurales. Ministerio de Educación. 1990.

${ }^{53}$ La educación del siglo XXI debe incluir bastante investigación y. por ello, los maestros deben mantener contactos con los investigadores.

${ }^{54}$ Existe un informe con los comentarios de los participantes en algunos microcentros que operan en el Departamento del Huila. César Vera y Francisco Parra, "Microcentros y formación docente", Boletín del PPE, No. 22, Orealc, agosto de 1990. pp. 54-65.

\footnotetext{
${ }^{55}$ A. Iran-Nejad, W. McKeachie y D. Berliner, "The multisource nature of learning: an introduction", Review of Educatínal Research, Vol. 60, No. 4, invierno de 1990, p. 511.

${ }^{56}$ Programa Escuela Nueva, La recuperación cultural y los agentes educativos, Ministerio de EducaciónMuseos de Artes y Tradiciones Populares-Unicef, Bogotá, 1990. 
mayor procesamiento (incluyendo su puesta al día periódica) y utilización en experiencias de aprendizaje: las artesanías locales, trabajos y actividades económicas, problemas de salud, geografía, paisajes, transportes, deportes, danzas, comida, animales, vegetales, semillas, minerales y las piedras. De vez en cuando, los textos sugieren la preparación de monografías sociales y culturales (que pueden ser evaluadas comparando con trabajos hechos en los años anteriores). Los maestros son estimulados para organizar reuniones con padres para discutir el material preparado por los alumnos. Los niños también participan en actividades de salud, sanidad, y nutrición ${ }^{57}$. Cerca de un $83 \%$ de la muestra de escuelas que en 1987 usaban el método Escuela Nueva tenían organizadas actividades de salud. Así, poco a poco, la escuela llega a ser un recurso de información para el maestro (que aprende acerca del entorno), para las agencias que operan en otros sectores de actividad económica y, eventualmente, para la comunidad misma.

\section{Usar el trabajo de grupo para pensar mejor y aprender a participar}

Trabajar en grupo es una de las maneras en que los alumnos de Escuela Nueva (y también los maestros como se comentó anteriormente) aprenden a enfrentar la incertidumbre que está presente cuando las actividades tienen múltiples respuestas válidas, como son las que presentan los textos de autoaprendizaje. También permite desarrollar valores democráticos tales como tolerancia a otras opiniones ${ }^{58}$. Los maestros pueden asesorar el trabajo interdependiente que se necesita para enfrentar la incertidumbre, o intolerancia gracias a la relación colegiada que desarrollaron en los microcentros. Los alumnos preparan de manera conjunta trabajos escritos, pinturas, maquetas, objetos o juegos, pero estos trabajos se basan usualmente en trabajos previos individuales cuando es posible (los textos incluyen instrucciones para el trabajo individual y luego para el grupal). Así, los maestros sólo necesitan evaluar un resultado final del grupo (en vez de cuatro o cinco individuales) y cada alumno autoevalúa su trabajo con el resultado del grupo. Sin embargo, de vez en cuando se califica al grupo de alumnos con el promedio de los trabajos individuales para hacer que los participantes se ayuden a aprender entre sí, en vez de simplemente completar un trabajo ${ }^{59}$. Los grupos rápidamente desarrollan mecanismos para alcanzar consenso, pero cuando existen serios desacuerdos el profesor debe ser el facilitador capaz de mostrar una manera de superar las diferencias.

Trabajando solos, en pares, cuartetos, o grupos más grandes, los alumnos suelen estar ocupados escribiendo sobre temas que ellos mismos han elegido. Los alumnos escriben acerca de cosas que conocen (o pueden indagar) y que les interesan. Los niños se consideran como recursos, y cada niño asume un rol específico en el grupo, tales como facilitador, secretario, relator o evaluador; al mismo tiempo los alumnos son responsables individualmente de completar sus hojas de trabajo en que describen sus experiencias. Ellos se ayudan entre sí, compartiendo ideas y habilidades para hacer sus trabajos. También aportan sus conocimientos y juicios. En resumen, lo que se dicen unos a otros es importante. Trabajar en grupos o equipos significa que los alumnos tienen que utilizar sus habilidades para escuchar, cooperar y llegar a acuerdos. El potencial surge de las diferencias en los estilos de aprendizaje de los estudiantes; es lo que permite a un

\footnotetext{
${ }^{57}$ Ministerio de Educación, La supervivencia y el desarrollo infantil para maestros de Escuela Nueva, Unicef, Bogotá, 1990.

${ }^{58}$ La "Red de usuarios" facilita el aprendizaje mutuo y desarrolla un enfoque "colegiado" muy dinámico. Ver Flechsing y Schiefelbein, Op cit.

59 D. Strother. "Cooperative learning: fad or foundation for learníng"? Kappan, Vol. 72, No.2, octubre de 1990, pp. 158-162. 
estudiante ofrecer una mejor sugerencia, en un caso, y que sea otro estudiante el que guíe al grupo para enfrentar un desafío diferente.

\section{Enseñanza compensatoria tutorial usando estrategias niño-a-niño}

La Escuela Nueva trata de prevenir los fracasos de lectura en el primer grado dando tutoría "uno-a-uno" a los alumnos que se identifican con riesgo de fracaso en lectura ${ }^{60}$. Actúan como tutores buenos alumnos de grados más altos (en algunos casos padres voluntarios) siguiendo las instrucciones que aparecen en las Guías del Profesor. Los tutores (a veces estudiantes avanzados del mismo curso que ya han terminado su trabajo) toman a los alumnos lentos de su clase en sesiones de 20 minutos mientras se desarrolla el periodo de estudios sociales. En general, los tutores elevan el rendimiento de los alumnos en el currículo regular de lectura. Por ejemplo, si en el currículo regular de lectura el profesor está trabajando en la letra "M", también lo hace e1 tutor. Sin embargo, los tutores pueden ser entrenados para usar una estrategia diferente a fin de enseñar la misma habilidad. Esta estrategia "uno-en uno es consistente con las investigaciones que muestran que la "cantidad de tiempo dedicada a la lectura durante el período de lectura contribuye significativamente para que los alumnos eleven su rendimiento en lectura" ${ }^{\text {. }}$.

\section{Desarrollar valores mediante el Gobierno Escolar (Consejo Estudiantil)}

Los niños se inician en la vida cívica y democrática a través de la elección del consejo estudiantil y luego participando. El Consejo Estudiantil es elegido dos o tres veces al año. A través de la participación en el Consejo Estudiantil los niños aprenden a actuar con autoridad y responsabilidad en la organización y el manejo de la escuela, pero también logran integrar procesos cognitivos con procesos que envuelvan actitudes sociales, afectivas y de desarrollo moral. Durante el primer taller se entrena a los maestros de la Escuela Nueva en desarrollar dentro de la escuela esas estructuras organizacionales e inducir democráticamente los roles de liderazgo que puedan ser más tarde replicados en el más amplio contexto de la vida adulta. El presidente del Consejo Estudiantil es usualmente un niño que piensa organizadamente y que habla bien; trabaja apoyado por los jefes de los diversos comités. Los alumnos organizados en comités se hacen responsables del aseo, mantenimiento, deporte, jardín escolar, el diario del colegio, biblioteca, recreación, adornos escolares (una sala de clases bien adornada aumenta el rendimiento) y disciplina y cooperan en el proceso de enseñanza a través de la supervisión o ayudando a estudiar a los estudiantes más lentos. A través de su participación en estas actividades los alumnos desarrollan actitudes de solidaridad, tolerancia (a las diferencias) y cooperación. Es una parte esencial del currículo y ayuda a crear vínculos adicionales entre la escuela y la comunidad ${ }^{62}$.

\section{Evaluación y Promoción Modular en vez de repetición de grado}

Al reconocer, tanto las diferencias en las aptitudes de los alumnos como las inevitables ausencias de los alumnos (faltar a clases) durante algunos períodos de las actividades

\footnotetext{
${ }^{60}$ Estrategias similares se han aplicado en otros proyectos. B.Otaala y R. Myers, Children caring childreri; new applications of an old idea. The consultative group on early childhood care and development, 1988; H.C.A. Somerset, Child to child: a questionnaire review and studies of projects en three countries, London University Institute of Child Health and Education, 1988.

${ }_{61}$ B. Taylor, B. Frye y G. Maruyama, "Time spent reading and reading growth". American Educational Research Journal, Vol. 27, No. 2, Pp. 351-362, verano de 1990.

${ }^{62} \mathrm{Sin}$ embargo, las principales relaciones con la comunidad se generan a través del uso de ejemplos de la vida diaria en las experiencias de aprendizaje que los alumnos llevan a cabo al seguir las instrucciones de los módulos.
} 
agrícolas, la Escuela Nueva usa promoción flexible y permite a los alumnos progresar a sus propios ritmos. Los alumnos avanzan por unidades de módulos en vez de grados y el profesor pone atención en la evaluación de las tareas y en la necesidad de que participen en programas compensatorios (con la ayuda voluntaria de monitores-estudiantes, comités o comunidad). Cada módulo incluye autoevaluación en su sección final, siempre que sea posible. Los alumnos usan información acerca del tema del módulo en un contexto diferente, llevan a cabo o comentan posibles aplicaciones y comparan con trabajos realizados en años anteriores a fin de autoevaluar sus propios informes y mejorarlos (autoevaluación formativa). De ahí que la ausencia por enfermedad o el retirarse para trabajar en la cosecha no obliga a "repetir grado el próximo año" (y aprender por segunda vez lo que ya se aprendió), sino simplemente continuar aprendiendo en el módulo siguiendo al último que aprobó antes de ausentarse. Esta estrategia beneficia especialmente a los alumnos de familias pobres con altos niveles de repetición. En todo caso, la evaluación formativa ayuda a los alumnos a dominar cada secuencia de módulos y a las decisiones que adoptan los maestros en los casos especiales. Conviene recordar, además, que la posibilidad de calificar o comentar únicamente el trabajo final al grupo reduce la cantidad de tiempo que los maestros dedican a la evaluación.

\section{Lo. Teoría educativa que fundamenta la Escuela Nueva}

La Escuela Nueva, como tantas otras innovaciones educativas, se basa en conceptos claros y en una sólida teoría educativa, pero utiliza el texto de una manera nueva y entrena al profesor al mismo tiempo que trabajan los alumnos ${ }^{63}$. La Escuela Nueva forma maestros ayudándoles a aplicar buenos principios pedagógicos bien probados y modelos que forman parte de un proceso flexible "demostración-entrenamiento-texto-demostraciónequipamiento- seguimiento". Una vez que se pone en práctica, la Escuela Nueva ofrece enseñanza activa y oportunidades para tomar decisiones; enfatiza la comunicación escrita, una estrecha relación entre la escuela y la comunidad y una evaluación frecuente (pero flexible) adaptada al estilo de vida de los niños de niveles pobres. Sin embargo, todos estos principios pedagógicos básicos ya han sido enunciados y experimentados por Pestalozzi, Herbart, Dewey ${ }^{64}$ Freinet, Makarenko o Montessori. Dichos principios han probado estar relacionados con niveles superiores de rendimiento académico según los resultados de investigaciones recientes ${ }^{65}$. También los diversos modelos de educación usados en Escuela Nueva — proyecto; exploración de campo; feria educativa o centro didáctico; taller educativo; red de usuarios; instrucción programada o tutoría- ya han sido descritos $^{66}$. En realidad, los dos nuevos elementos peculiares de Escuela Nueva son que todos estos principios y modelos se presentan en una secuencia de trabajo determinada por el texto de autoaprendizaje (cuyo conjunto de módulos que se organiza en cada escuela con su maestro) que ayuda al maestro a ser entrenado gradualmente en el mismo trabajo y que el "modelo Escuela Nueva" ha pasado la prueba de ser aplicado en una escala nacional.

Escuela Nueva primero moviliza a los maestros a través del desarrollo de una visión compartida que se inicia en la visita inicial a la escuela de demostración. Luego da

\footnotetext{
${ }^{63}$ Esto suele ser cierto en muchas innovaciones. Ver, por ejemplo, Sheldon Shaeffer, Educational change en Indonesia, IDRC-MR270e, Ottawa, octubre de 1970, p. 85.

${ }^{64}$ Ya en 1920 John Dewey enfatizaba en la necesidad de enseñar ciencia como búsqueda. John Dewey, How we think, Heath, Boston, 1910.

${ }^{65}$ R Slavin, N. Madden, N. Karweit, B. Livermon y L. Dolan, "'Success for all: first-year outcomes of a comprehensive plan for reforming urban education", American Educational Research Journal, Vol. 27, No. 2, pp. 255-278, verano de 1990.

${ }^{66}$ Flechsing y Schiefelbein, "Catálogo de modelos didácticos" [Versión 1985-1986], Documento de Trabajo No. 4, CIDE, Santiago de Chile, 1985.

Digitalizado por RED ACADEMICA
} 
oportunidades para que el maestro continúe su desarrollo al exponerlo a un conjunto de principios que forman parte de la secuencia de actividades sugeridas en el material de autoaprendizaje. La Escuela Nueva opera como una combinación de enfoques que están presentes, al mismo tiempo, en todas las actividades escolares y que son cada vez mejor implementados a medida que el maestro: se siente más y más confortable en su nuevo rol de líder; comparte en mayor grado los objetivos educativos de EN y aprende a colaborar con sus colegas. La descripción de estos enfoques se presenta en los párrafos siguientes y el desarrollo gradual del experimento se presenta en el capitulo 6.

\section{Participación y beneficios de todos los involucrados en Escuela Nueva}

El programa Escuela Nueva promueve la participación de cada maestro, niño y miembros de la comunidad no sólo en el proceso educativo, sino en el mejoramiento de la calidad de vida de todos los habitantes. Para esto los textos generan contactos permanentes de los alumnos con la comunidad, se entrena al maestro en realizar actividades específicas, se elevan las satisfacciones profesionales y se ofrecen oportunidades para aprender acerca de la comunidad. Los contactos y el entrenamiento se ofrecen en cada clase diaria y en el trabajo en los microcentros una vez al mes.

Escuela Nueva trata de maximizar la participación del alumno en diversos niveles discusión de toda la clase, grupos cooperativos y proyectos individuales - integrando su cultura y su conocimiento previo en la mayoría de las experiencias de aprendizaje a fin de hacer que la sala de clases sea un ambiente acogedor y que la enseñanza sea más pertinente $^{67}$. Al sentir el alumno que su cultura es valorada aumenta su autoestima y, por lo tanto, también aumenta su rendimiento ${ }^{68}$. Al mismo tiempo, los alumnos aprenden a aprender por su propia cuenta y a progresar hacia su autodeterminación a medida que toman decisiones y usan sus conocimientos previos en las experiencias de aprendizaje ${ }^{69}$.

De acuerdo con los resultados de investigaciones recientes ${ }^{70}$ Escuela Nueva eleva el aprendizaje de los alumnos gracias a la participación activa de los padres en el aprendizaje de sus niños. Escuela Nueva ofrece a los padres, parientes y comunidad la oportunidad de participar en debates sobre actividades escolares, para que sientan que ellos generan cultura (como lo hace notar Paulo Freire), que su cultura es valiosa al integrarla en las actividades diarias de la escuela (a través de la gran cantidad de ejemplos locales incluidos en las experiencias de aprendizaje), y que tienen oportunidades para hacer contribuciones importantes ${ }^{71}$. Por ejemplo, al artesano local capaz de preparar greda se le pide que le enseñe a los niños chicos a manipularla para moldear sus prime-ras letras ${ }^{72}$. Como resultado de esa actividad el artesano participa en

\footnotetext{
${ }^{67}$ Estrategias similares se han usado en experiencias de personalización de la enseñanza. McLaughhin y J. Tahbert, "Constructing a Personalized school environment", Kappart, Vol. 72, No. 3, noviembre de 1990 , pp. 230-235.

${ }^{68}$ El currículo puede ser de interés para toda ha comunidad. Por ejemplo, si se incluyen temas como cuidado de los niños se puede diseminar informaciones importantes que pueden facilitar que sobrevivan los hermanos.

${ }^{69} \mathrm{El}$ darse cuenta de que tienen estrategias para aprender facilita la participación y responsabilidad de los alumnos y hace que su educación sea más satisfactoria y efectiva. Ver: C. B. Chadwick, "Estrategias cognoscitivas y afectivas de aprendizaje", Revista Latinoamericana de Psicología, Vol. 20, No.2, 1988. pp. 163-205.

${ }^{70}$ Roda M. Becher, Parental Invoivement: a Review of Research and Principies of Suecessful practica, National Institute of Education, Washington D.C., 1984.

${ }^{71}$ El plan de Chicago para permitir que las escuelas asignaran su presupuesto y la mayor participación de los padres es otro ejemplo. Ver Ann Lieberman and Lynne Miller, "Restructuring Schools: What matters and what Works", Kappan, Vol. 71, No. 10, junio de 1990, p. 761.

${ }^{72}$ Se usa aquí el modelo "tutoría". Ver: Flechsing y Schiefelbein, op cit. 
las actividades escolares y su trabajo es valorado, el profesor obtiene materiales de aprendizaje y los niños aprenden a leer de una manera interesante ${ }^{73}$.

\section{Las tareas de aprendizaje se unen con La vida diaria}

La Escuela Nueva une la enseñanza de habilidades intelectuales con aplicaciones de la vida diaria para dar a los alumnos un sentido de realidad. Al unir la enseñanza de habilidades con ejemplos de la vida diaria se estimula la expresión y el análisis escrito, el pensamiento matemático y la comprensión de lo que se ha leído. Este enfoque es especialmente importante para los alumnos de niveles socioeconómicos bajos que a menudo ven menos interés o significado en las actividades que desarrollan habilidades que los alumnos con más recursos; de ahí que los primeros necesiten ayuda para encontrar el significado de lo que hacen en la escuela. El material de lectura de Escuela Nueva no sólo refleja y respeta las experiencias vivénciales y la cultura de los estudiantes, sino que también les pide que lleven a cabo actividades libres tales como escribir cartas acerca de problemas locales o tratar de ejercitar una habilidad en una actividad local.

\section{Escribir para pensar de manera sistemática y para intercambiar opiniones}

El área escritura del currículo de la Escuela Nueva enfatiza la comunicación escrita (significativa) como el paso final de un proceso de pensamiento. La Escuela Nueva da especial valor a la escritura como ayuda los alumnos para explorar, organizar y refinar sus ideas acerca de ellos mismos y para construir y presentar sus propias interpretaciones del contexto y de otros temas ${ }^{74}$. Los textos de autoaprendizaje aprovechan las experiencias y conocimientos previos de los alumnos así como también otras experiencias que les son menos familiares a los estudiantes (especialmente en los materiales que se usan para la autoevaluación). La Escuela Nueva pone menos énfasis en aprender los mecanismos del lenguaje escrito (ortografía, puntuación, 0 gramática) ${ }^{75}$ desligados del acto de comunicarse por escrito. Más aun, Escuela Nueva reconoce la importancia de unir lectura, escritura y expresión oral ${ }^{76}$. Los textos de autoaprendizaje integran todos los aspectos del enseñar a leer al hacer que lean y discutan lo que ellos han escrito o de hacerlos escribir acerca de lo que han leído. Los textos indican en cada momento del proceso de aprendizaje cuándo los alumnos deben hacer algún trabajo escrito. Los textos sugieren que los grupos reescriban los trabajos individuales a fin de reducir el tiempo que el maestro dedica a poner notas o hacer evaluación formativa de trabajos escritos. En todo caso, los maestros tienen tiempo para esta actividad dado que las instrucciones y la información (rutinarias) ya están absolutamente disponibles en los libros.

\footnotetext{
${ }^{73}$ Cuando el alumno interroga a su madre sobre la receta de la comida favorita (actividad que puede terminar con la madre preparando ese guiso con los alumnos del grupo en la escuela); cuando le pregunta a su abuelo cómo era el pueblo hace 30 o 50 años o cuando le pregunta al padre sobre cómo realiza su trabajo y escribe cuidadosamente las respuestas que serán comentadas en la escuela se produce un encuentro natural entre la escuela y la vida.

${ }^{74}$ El aprendizaje puede ser parte de un proceso de "descubrimiento", porque a veces los niños no saben lo que van a decir hasta que hablan. J. Britton, Prospect and retrospect: Selected essays, Boynton/Cook, 1982, p. 110.

${ }^{75}$ Las dificultades para evaluar lo que escriben los alumnos ha llevado a aplicar exámenes sobre gramática y ortografía. Ver Brian Fluot, "The literature of direct writing assessment: major concerns and prevailing trends", Review of Educational Research, Vol. 60, No. 2, pp. 23 7-263. El tiempo que requiere el profesor para evaluar lo que escribe cada alumno es también un factor para dar prioridad a la gramática que EN resuelve con los informes de grupo (a partir de los informes individuales).

${ }^{76}$ R. Durst y G. Newell, "The uses of function: James Britton's category system and research on writing", Review of Educatiortal Research, Vol. 59, No. 4, invierno de 1989, pp. 375-394.
} 


\section{Tomar decisiones para mejorar la motivación y el pensamiento}

Cada vez que los alumnos toman una decisión en relación con su aprendizaje se comprometen acerca de sus implicaciones y llevan a cabo un proceso sistemático de pensamiento. Los alumnos de Escuela Nueva suelen estar absortos en sus tareas, interesados y trabajando con ánimo, porque, entre otras cosas, trabajan con ejemplos que les interesan y que tienen significado para ellos. Los textos de autoaprendizaje los fuerzan a tomar muchas opciones (dentro de un marco curricular global que asegura que todos desarrollen habilidades de nivel similar) ${ }^{77}$. Por ejemplo, deben seleccionar: ¿Qué historias locales estudiaremos? ¿Cómo expresar las ideas acerca de esas historias? ¿Quién puede informar acerca de ese problema? ¿Cuánta información se puede combinar con los dibujos para crear un gran afiche? La regla es esta: siempre que el texto de autoaprendizaje pueda dar al alumno una opción de cualquier tipo, debe darla. La única cosa mejor que tener a los alumnos eligiendo entre una gran variedad de maneras de aprender es (usualmente después de que la Escuela Nueva ha operado durante un par de años y los profesores se sienten cómodos) hacer que generen sus propias opciones. Una evaluación del nivel de opciones de los alumnos de las escuelas tradicionales debería incluir, por lo menos, las siguientes cuatro preguntas: ¿Cuán a menudo los alumnos llevan a cabo una opción en la sala de clases? ¿Cuán a menudo los alumnos sienten que tienen el control de ellos mismos? ¿Cuántas decisiones (que realmente cuentan) hacen los alumnos? ¿Cuán a menudo los alumnos sienten que son importantes en su sala de clases $^{78}$ ? El principio subyacente es que en el siglo XXI se necesitan nuevas mentes y que la lectura, escritura y matemáticas no son actos naturales de la mente ${ }^{79}$. De ahí que el dar opciones a los alumnos podría ayudar a crear ese tipo de mente nueva, adecuada a las demandas del nuevo siglo.

\section{Asegurar que los profesores tengan tiempo para ser facilitadores del proceso de aprendizaje}

Los maestros de Escuela Nueva, pueden tener una larga entrevista con un solo alumno, porque el resto de los alumnos está absorto en su propio trabajo y los miembros del consejo estudiantil solucionan muchos de los problemas de disciplina. Cuando los alumnos están ocupados compartiendo ideas y habilidades, el maestro puede escuchar con atención al alumno con que está conversando. El material de instrucción reduce la cantidad de tiempo que los maestros dedican a dar instrucciones o entregar información rutinaria (que puede estar escrita en un texto). Los maestros de Escuela Nueva, tal como los buenos cirujanos o violinistas, son capaces de adaptar las técnicas pedagógicas o el tiempo de aprendizaje, pero no se espera que creen toda una nueva técnica en cada clase. Por otro lado, entre más tiempo trabajen con el estilo de la Escuela Nueva desarrollan una mayor capacidad y más frecuentes tienden a ser los ajustes. En todo caso, mientras más experiencia se tenga, más preparado estará el maestro de Escuela Nueva para adecuar el método a las diferencias individuales. Implementar la Escuela Nueva no deberla afectar el tiempo libre de los profesores (más allá del horario regular de trabajo) y aun el uso de su propio tiempo regular suele ser más eficiente que, en las escuelas tradicionales.

\section{El aprendizaje para el dominio es clave para un alto rendimiento académico}

\footnotetext{
${ }^{77}$ Observar, clasificar, describir, comparar, inferir, deducir, evaluar o tomar decisiones.

${ }^{78}$ Carolyn Mamchur. "But ... the curriculum”, Kappan, Vol. 71, No. 8, abril de 1990, p. 636.

${ }^{79}$ Robert Ornstein y Paul Erhlich, New World New Mind, Doubleday, 1989.

Digitalizado por RED ACADEMICA
} 
La Escuela Nueva presenta sus textos organizados en módulos o unidades cortas (entre 8 a 10 horas de clases). Las lecciones se presentan en textos escritos, aunque existen oportunidades para que los maestros presenten lecciones (especialmente en los casos en que los alumnos no requieren de conocimientos previos). Los alumnos trabajan estos módulos o lecciones a su propio ritmo; y los estudiantes autoevalúan su trabajo comparándolo con otros trabajos o dando pruebas de evaluación formativa al final de cada unidad $^{80}$. Los maestros deciden qué alumno falló en la evaluación final (sumativa) y dan a esos alumnos ayuda individual o grupal en el tema del módulo antes de avanzar a un material nuevo (o selecciona alumnos más antiguos para dar la ayuda). En resumen, la Escuela Nueva busca un equilibrio entre el aprendizaje para el dominio (Learning for mastery, LFM) desarrollado por Bloom con énfasis en el profesor y el Sistema de Instrucción Personalizado (PSI) de Keller con énfasis en los materiales escritos ${ }^{81}$.

\section{La evaluación de los efectos de la Escuela Nueva es parte integral de la experiencia}

El pilar del desarrollo de la Escuela Nueva ha sido la crítica sistemática de la práctica pedagógica a partir de los seis criterios examinados en este capitulo y la voluntad para modificarla con miras a mejorar el aprendizaje. En la medida que estos seis criterios, comentados en las secciones anteriores sean aceptables, también pueden ser usados para seleccionar nuevas alternativas ${ }^{82}$. El modelo Escuela Nueva tiene ahora tres modalidades de evaluación continua: los informes preparados por los supervisores y coordinadores de microcentros locales; las investigaciones empíricas sobre rendimiento y los factores que lo determinan ${ }^{83}$ y observaciones de los expertos que han estado visitando el proyecto en los últimos años ${ }^{84}$. Los microcentros y la red de capacitación se han convertido en una continua fuente de valiosa información evaluativa. Esta fuente ha sido un buen mecanismo, de bajo costo, para mantener un control en la calidad durante el proceso de expansión a la escala nacional en la Colombia rural. Los resultados de las investigaciones y las observaciones de las agencias internacionales serán comentadas en el capítulo 7 como parte de la descripción del desarrollo del proceso de experimentación de la Escuela Nueva.

\section{La expansión desde un proyecto piloto hasta una reforma masiva de nivel nacional}

La Escuela Nueva ha cambiado gradualmente el centro del interés desde la "buena enseñanza", desarrollada en las escuelas unitarias auspiciadas por Unesco en la década del sesenta, hasta un "buen aprendizaje" que usa múltiples experiencias de aprendizaje diseñadas con gran cuidado. En este capitulo cada educador podría identificar las principales etapas de esta transformación y examinar más adelante, en la Parte III, las condiciones para replicar la experiencia en otros contextos.

\section{Las raíces de la Escuela Nueva provienen de las escuelas multigrado de los años 60}

\footnotetext{
${ }^{80}$ uso de pruebas para aumentar el rendimiento en los alumnos de la educación primaria. Ver E. Cabezón, "The effects of marked changes en student achievement pattern on the students, their teachers, and their parents: the Chilean case", Thesis, University of Chicago, 1984.

${ }^{81}$ C. Kulic, J. Kulic y R. Bangert-Drowns, "Effectiveness of Mastery Learning programs: a Meta Analysis", Review of Educational Research, Vol. 60. No. 2. verano de 1990, pp. 265-299.

${ }^{82}$ Un criterio adicional podría ser el uso de grupos de trabajo para reducir la incertidumbre que generan tareas con respuestas. Este criterio forma parte del modelo de EN, pero se puede usar para evaluar futuros desarrollos.

${ }^{83}$ C. Rojas y Z. Castillo, Op cit.

${ }^{84}$ Este informe es un ejemplo del efecto de haber visitado escuelas que funcionan con el modelo EN. 
La idea del aprendizaje activo ya fue destacada en el Primer Proyecto Principal de Educación de América Latina, auspiciada por Unesco-Orealc en los años 60. La enseñanza en multigrado, promovida en las Escuelas Normales que cooperaban con el Proyecto Principal, utilizaba "fichas o guías de enseñanza" que fueron probadas en una muestra de escuelas rurales. La metodología de Escuelas Unitarias (MEU) se basó en las ideas de la escuela activá ${ }^{85}$. En múltiples misiones $A$. Covarrubias y $S$. Hernández R. llevaron a cabo una cruzada para experimentar las escuelas de multigrado en una docena de países ${ }^{86}$. Su trabajo se vio respaldado con la aprobación mundial de las Escuelas Unitarias por los ministros de Educación en una reunión realizada en Ginebra en 1961. La enseñanza individualizada, aprendizaje activo, uso de libros y guías, escuela primaria completa, enseñanza en multigrado (escuela sin grados), múltiples pizarrones (uno por grupo) y promoción continua (automática) eran las principales características de la metodología de la Escuela Unitaria ${ }^{87}$. Algunas escuelas Unitarias ensayaron con éxito los materiales de instrucción personal de bajo costo desarrollados en el Instituto Brasileño de Educación, Ciencia y Cultura (IBECC) $)^{88}$.

La primera Escuela Unitaria en Colombia se organizó en el "Instituto Superior de Educación Rural" en Pamplona, Norte de Santander, con el auspicio del Primer Proyecto Principal. Más adelante, en 1967, el gobierno colombiano decretó la extensión de este método a todas las escuelas de maestro único. Se entrenó a más de 4.500 maestros en 160 seminarios cortos en los dos años siguientes y se preparó y distribuyó un Manual del maestro a esos profesores. En Colombia el movimiento de la Escuela Unitaria tomó fuerza y la Universidad de Antioquia comenzó a experimentar el modelo en 1968. A principios de los años setenta se experimentaban varios modelos alternativos en todo el país en que cada uno respondía a una dimensión particular del problema educativo ${ }^{89}$.

\section{Los textos de autoaprendizaje reemplazan las fichas de enseñanza}

En los años 60 el aprendizaje activo para que los niños avanzaran a su propio ritmo se basó en las Fichas de enseñanza y en los libros tradicionales. Los maestros y los alumnos más antiguos dedicaban largas horas a preparar esas Fichas. Algunos de ellos continuaron trabajando por algún tiempo, dada la gran satisfacción que producía el alto rendimiento de sus alumnos con relación al de los alumnos de las escuelas tradicionales. Sin embargo, muchos profesores se agotaron por la gran cantidad de trabajo adicional necesario para preparar las Fichas de enseñanza, por la falta de apoyo de colegas y supervisores y por las deficiencias observadas cuando los alumnos trabajaban con un currículo con contenidos inapropiados o con profesores que continúan en un enfoque expositivo en vez del sistema activo. El movimiento de las Escuelas Unitarias estaba perdiendo su dinámica cuando un grupo comenzó a imprimir y encuadernar las Fichas de enseñanza generando así en un nuevo tipo de texto de autoaprendizaje en afortunada contradicción a lo que sugería Dottrens que no quiso publicar sus fichas para que cada profesor fuera un creador, con lo que impidió la posibilidad de acumular su valioso aporte al conocimiento pedagógico.

\footnotetext{
${ }^{85}$ R. Dottrens, Individualized Education, Suiza, 1949.

${ }^{86}$ Alejandro Covarrubias, "Los avances de la escuela primaria completa en el medio rural", Boletín de Educación, No. 4, OREALC, Santiago de Chile, julio-diciembre de 1968, pp. 30-39.

${ }^{87}$ Ministerio de Educación, "Organización y funcionamiento de la escuela completa", Cuadernos de la Superintendencia, No. 11, Santiago de Chile, septiembre de 1967, p. 107.
}

${ }^{88}$ A. Covarrubias [Seminario de Sao Paulo], "Hechos e Ideas", Boletín de Educación, No. 5, OREALC, enero-junio de 1969, pp. 31-37.

${ }^{89}$ Vicky Colbert, "Universalización de la primaria en Colombia. El programa de Escuela Nueva”, en La Educación Rural en Colombia, FES, Bogotá, 1987, pp 77-93. 


\section{Un grupo colombiano comienza a dar forma al modelo de Escuela Nueva}

El éxito generado al transformar el set de fichas de enseñanza en un texto de autoaprendizaje y mejorar la pertinencia del currículo fue inmediato y el grupo que promovió ese cambio se sintió motivado para mirar otras causas de la baja calidad de la educación y del fracaso. Detectaron como causas importantes la estructura legal y administrativa; los conflictos con los supervisores; el no considerar las condiciones de trabajo de los maestros y la falta de recursos para llevar a escala nacional la experiencia. El grupo promotor se puso de acuerdo en que un error importante había sido tratar de transferir productos más que procesos ${ }^{90}$. El Programa de Escuela Nueva (descrito en el capítulo 5), buscó superar el método de las Escuelas Unitarias y a mediados de los setenta se puso a buscar el grupo promotor una respuesta a todas estas causas del fracaso. El grupo promotor siguió trabajando ${ }^{91}$ y enfatizó la replicabilidad de los materiales y los procesos y la factibilidad económica. En otras palabras, Escuela Nueva incluyó, desde su diseño, la intención de llegar a la escala nacional ${ }^{92}$. El grupo promotor comenzó un lento proceso de difusión para convencer a los expertos en currículo que se podía lograr un aprendizaje eficiente de una manera no tradicional y demostrar a los inspectores que no se infringían las normas vigentes. También calmaron a los expertos que reclamaban que los maestros no habían seguido un curso especial en educación individualizada. Afortunadamente, un número creciente de padres y maestros rurales empezó a pedir los materiales y los métodos de Escuela Nueva para aplicarlos en sus escuelas, lo que acalló muchas críticas. En todo caso, cada vez que aparecían nuevos problemas el grupo promotor trató de solucionarlos, para lo cual a veces invitó a los mismos críticos a participar en la búsqueda de soluciones. A fin de prevenir dificultades, cada vez que se ha nombrado a un nuevo funcionario superior en el Ministerio de Educación el grupo lo ha invitado a visitar alguna Escuela Nueva. Esta estrategia ha sido especialmente efectiva para proteger la continuación del programa.

\section{La lucha contra los intereses, las rutinas y la burocracia}

El grupo promotor de Escuela Nueva dedicó muchas horas para lograr el apoyo de grupos de poder que podrían quedar afectados por Escuela Nueva. La industria del libro (incluyendo a los autores de los libros de texto) estaba preocupada de que los textos de autoaprendizaje de Escuela Nueva fueran impresos por el Estado. Pero la industria se benefició por la venta de los 100 libros para las bibliotecas de aula y finalmente se dio cuenta de que Escuela Nueva estaba desarrollando un amplio mercado para sus libros. A largo plazo, sin embargo, se debería lograr la participación de la industria privada en el diseño y producción de mejores libros de autoaprendizaje.

Los expertos en currículo criticaron Escuela Nueva en términos de sus objetivos y contenidos, más que en términos de los procesos de aprendizaje y el grupo promotor de Escuela Nueva dedicó largas horas para aclarar que la mayoría de las diferencias eran más bien semánticas que sustantivas. Se enfrentaron problemas similares para introducir el enfoque de aprender haciendo (taller) más que el oír conferencias y la lectura tradicional sobre teorías de enseñanza y aprendizaje.

\footnotetext{
90 Vicky Colbert, Transferencia de tecnología educativa en Colombia, Colciencias/ OEA/Ministerio de Educación, Bogotá, 1979.

${ }^{91}$ Liderados por Vicky Colbert de Arboleda y Oscar Mogollón e integrado por un grupo de profesores rurales, supervisores, profesores universitarios de Norte de Santander y un grupo del Ministerio de Educación.

${ }_{92}$ V. Colbert y 3. Arboleda, "Universalization of Primary Education en Colombia: The New School Programme”, Notes, Comments No. 191. Unesco/Unicef-WFP Co-operative Programme, Paris, julio 1990. 


\section{El Grupo Promotor aprendió que Escuela Nueva debe ser efectiva y eficiente}

Con el apoyo económico de Usaid se implementó el programa Escuela Nueva en 500 escuelas de tres regiones (departamentos) durante 1975 y 1978. Los materiales para los alumnos y maestros fueron revisados con cuidado; durante la implementación se tomó en cuenta la organización administrativa y financiera de las regiones; se pusieron al día los calendarios y los materiales para el entrenamiento; se mejoró la producción y distribución de los materiales y se contrató a una institución de prestigio para llevar a cabo la primera evaluación. Como resultado de este trabajo el grupo promotor pudo constatar que los alumnos de Escuela Nueva obtenían mejores puntajes en los tests nacionales que los alumnos de escuelas tradicionales; el programa de Escuela Nueva era efectivo ${ }^{93}$. Durante el periodo 1979-1986 se amplió el programa Escuela Nueva a 8.000 escuelas con financiamiento del Banco Interamericano de Desarrollo (BID), de fuentes regionales, de la Federación de Cafeteros (Fedecafe) y de la Fundación de Educación Superior (FES). Todo el programa fue revisado, cada vez, para asegurarse que los requerimientos de recursos por cada alumno atendido fueran reducidos sustancialmente.

\section{El desafío de ampliar la escala de aplicación obligó a realizar ajustes}

A principios de los años ochenta el grupo promotor aprendió a expandir la aplicación del programa. Con el apoyo del Banco Mundial el programa de Escuela Nueva se implementó en otras 10.000 escuelas y ahora un millón de alumnos colombianos participa en el programa Escuela Nueva. El grupo se dio cuenta que el entrenamiento cuidadoso y la estrecha supervisión escolar, que tuvieron un papel clave en el desarrollo del modelo de Escuela Nueva, tenía que modificarse la base para poner en práctica EN en una escala masiva ${ }^{94}$. El entrenamiento se simplificó a tres semanas de talleres cuidadosamente programados y que eran implementadas con un manual muy detallado ${ }^{95}$. En esos talleres los supervisores y los maestros podían simular el contexto de la sala de clases (dramatizaciones) y aprender a usar los materiales al realizar el trabajo tal como lo harían en el futuro los alumnos. De esta manera, al volver a sus escuelas podían replicar sin dificultades el mismo proceso de aprendizaje activo. Este enfoque hizo que el entrenamiento y, más adelante, la asistencia técnica fueran más fáciles de replicar.

La supervisión había sido concebida inicialmente como un proceso de seguimiento de los maestros entrenados para operar el programa de Escuela Nueva (enfatizando la función pedagógica de los supervisores más que la de inspección). Era difícil entrenar y asegurar este tipo de supervisión en forma masiva, por lo que el grupo llevó a cabo una búsqueda sistemática de formas alternativas de supervisión. A comienzos de los años ochenta el grupo se convenció de que la supervisión de escuelas debía reemplazarse por una animación que se llevaría a cabo en talleres mensuales no formales de menos de una docena de maestros de cada área (municipalidad). Este proceso de animación y seguimiento local se fue desarrollando gradualmente hasta ser conocido como el "sistema de microcentros". En 1985 fue declarado el procedimiento oficial de supervisión de Escuela Nueva. El microcentro permite la autoevaluación de los maestros, el compartir los problemas y soluciones, las innovaciones, las críticas, el análisis y el desarrollo de

\footnotetext{
${ }^{93}$ R. G. Myers, Going to Scale, Unicef, Nueva York, septiembre de 1984.

${ }_{94}$ Ministerio de Educación/Unicef, The New School Programme. More and better primary educatlon for children en rural areas, Bogotá, septiembre de 1990, p. 14.

${ }^{95}$ V. Colbert y O. Mogollón, Hacía la Escuela Nueva, Ministerio de Educación Nacional, Bogotá, 1977 (7a edición). 
pequeños proyectos para mejorar la escuela y la comunidad ${ }^{96}$. Mientras la supervisión escolar siempre tiene un potencial para hacer una contribución importante a la calidad de la educación ofrecida por la Escuela Nueva, los problemas estructurales (válidos para la mayor parte de América Latina) relacionados con la asignación del presupuesto para movilización, falta de un correo eficiente, dificultades de transporte, los malos caminos, la falta de teléfonos, los bajos niveles de salarios, las distancias y el aislamiento de las escuelas reducen la factibilidad de que exista una mayor contribución de los supervisores.

\section{Evaluación formativa de la implementación masiva}

Los "microcentros" han sido la mejor herramienta para enfrentar los problemas logísticos y para afinar los detalles de la puesta en práctica de la Escuela Nueva. Los problemas logísticos, enfrentados durante la transformación de las 20.000 escuelas rurales a Escuela Nueva hicieron que los Manuales del Maestro o los textos de autoaprendizaje llegaran demasiado temprano o demasiado tarde, con respecto a las fechas en que se realizaban los seminarios de entrenamiento. En algunas escuelas el trabajo preliminar con la comunidad no se completó a tiempo para el segundo seminario. Algunas de estas alteraciones del programa de introducción gradual de la innovación se detectaron a tiempo, pero otras sólo se detectaron en la evaluación llevada a cabo por el Banco Mundial en 1988. En todo caso se debe apoyar a los maestros para que dediquen suficiente tiempo a supervisar el progreso de los estudiantes en trabajo con los módulos (y recordarles que lo hagan si lo obvian).

Se debe evaluar con especial cuidado la operación del Consejo Escolar. Siempre está el peligro de transformar los líderes en tiranos. Los planes de trabajo para el Consejo Escolar deben generar actividades pertinentes, que incluyan el trabajo cooperativo de sus comités con grupos de la comunidad. La frecuencia de la elección de los miembros también debería ser revisada. Para algunos comités (por ejemplo, Cruz Roja) un período más largo (por ejemplo, cada seis meses) podría permitir a sus miembros un trabajo más serio, mientras que otros comités deben cambiar cada tres o cuatro meses para mantener motivados a sus miembros.

\section{TERCERA PARTE \\ ¿Qué hemos aprendido de Escuela Nueva? ¿Cuáles son las condiciones para replicar este tipo de innovación?}

Los educadores pueden extraer dos lecciones de los antecedentes presentados hasta aquí: (i) es económica y educativamente factible elevar la calidad de la educación de las escuelas públicas cine trabajan en áreas pobres, y (ii) hay que planificar e implementar cuidadosamente las estrategias y actividades para poner en práctica, si se quiere tener éxito en futuras experiencias similares. Estas dos lecciones y el usar el modelo de la Escuela Nueva en conjunto con otras estrategias se comentan en los dos capítulos siguientes y en el último capítulo se presentan las conclusiones y los nuevos desafíos.

Escuela Nueva constituye un ejemplo de escuelas que elevan su calidad a pesar de contar con recursos limitados (el costo por alumno de la Escuela Nueva es cerca de un $5 \%$ a un $10 \%$ más alto que el costo por alumno de las escuelas tradicionales). Además,

96 O.Mogollón, El microcentro y el proceso de educación permanente en Escuela Nueva, Ministerio de Educación, Bogotá, 1986. Programa Escuela Nueva: los microcentros rurales, Ministerio de Educación, Bogotá, 1990. 
es un programa que permite una expansión masiva porque está disponible en materiales escritos (instrucciones y manuales), con dimensiones y tiempos conocidos que pueden ser manejados por planificadores y adaptados a condiciones locales. Por lo tanto, el gran desafío para poner en práctica EN es la necesidad de reasignar los recursos usados en las escuelas tradicionales de acuerdo con las líneas del modelo ${ }^{97}$. El análisis de factibilidad de EN (y los elementos que deben ser tomados en cuenta para implementarla) ya se presentó en la Parte II, pero en este capítulo se presenta la evidencia de las evaluaciones y alguna información adicional sobre el contexto en el cual se llevaron a cabo las innovaciones.

La experiencia obtenida en la media docena de países que han tratado de implementar adaptaciones del modelo de Escuela Nueva y en otros intentos por cambiar la educación ${ }^{98}$ sugieren que la adaptación de Escuela Nueva debe tener en cuenta algunos aspectos claves del proceso. Siete de estos aspectos claves están resumidos en el capítulo 8. El capítulo 9 trata de identificar las futuras tareas y desarrollos del modelo de Escuela Nueva o de cualquier innovación destinada a elevar la calidad de la educación.

\section{Bajos costos por alumno y resultados positivos del programa de Escuela Nueva}

Aun cuando los costos unitarios puedan ser medidos con alguna precisión, ahora que 20.000 escuelas están operando el método de Escuela Nueva, y se ha medido el nivel de rendimiento en una muestra de escuelas, es todavía prematuro evaluar el impacto final del programa en la calidad de la educación. Estas dos mediciones se comentan en este capítulo. Sin embargo, no se comenta (ni toma en cuenta) el alto costo en que se incurrió en el período 1970-1985 para desarrollar el modelo $Y$ de Escuela Nueva (cerca de US\$ 15 millones) ya que a pesar de haber sido una inversión muy alta no debe volver a repetirse en las nuevas aplicaciones (los ajustes de los textos tienen un costo relativamente bajo) y por ello no debe afectar las decisiones de expandir Escuela Nueva a otras escuelas en Colombia o en otros países.

\section{Los costos unitarios de la Escueta Nueva son bastante más bajos de los esperados}

Los actuales costos de operación de Escuela Nueva son muy parecidos a los costos de las escuelas tradicionales. La comparación entre ambos costos se debe centrar en los costos de tres elementos: los libros de texto, las bibliotecas y el aula al entrenamiento de maestros. El costo de dar a cada alumno libros de autoaprendizaje (guias de estudio) para cuatro asignaturas en cada grado es US\$15, pero se tiene que entregar libros a los alumnos si se espera que puedan alcanzar los niveles mínimos de rendimiento. La típica biblioteca de 100 libros para la clase (o la escuela unitaria) cuesta entre US\$150 y US\$ 225. El entrenamiento por maestro cuesta en promedio US $\$ 82$ por año ${ }^{99}$. Estos costos hay que expresarlos por alumno y por año. Los textos y los libros de la escuela se usan durante un periodo de cuatro años, de ahí que el costo anual por alumno (suponiendo 30 alumnos por profesor) se reduce a US\$ 8.2, eso es como el $10 \%$ del costo anual actual (en realidad las diferencias serían de sólo US\$ 4.5 por alumno cuando ya se están entregando textos y, por ende, su costo no debería ser incluido como un incremento).

\section{Hay un impacto positivo en el rendimiento, pero sólo midió una parte de los beneficios}

\footnotetext{
${ }^{97}$ M. Lockheed y E. Hanushek, "Improving efficiency en developing countries: what do we know", Compare, Vol. 18, No. 1, 1988, pp. 21-38 (World Bank Reprint series, No. 435).

${ }^{98}$ Sheldon Shaffer, Educational change en Indonesia, IDRC-MR270e, Ottawa, octubre de 1970, p. 85.

99 US\$ 30 para viaje. Cinco días de viáticos a US\$ 8 por día; US\$2 para materiales y US\$10 para el instructor/animador. 
Las evaluaciones del programa Escuela Nueva han mostrado hasta ahora resultados positivos. Tanto los estudios de seguimiento como las opiniones de especialistas muestran que la Escuela Nueva ha mejorado las tasas de promoción, los puntajes de rendimiento y la autoestima, la satisfacción de los maestros, y el apoyo de las autoridades locales y de la comunidad. Comparaciones hechas en 1977 entre alumnos de Escuela Nueva y de escuelas tradicionales demuestran que, tanto en términos de rendimiento y de comportamiento cívico-social, como en términos de creatividad y autoestima el rendimiento de los alumnos de Escuela Nueva era significativamente más alto que el trabajo realizado por alumnos de escuelas tradicionales ${ }^{100}$. Pero hubo dudas en cuanto a los efectos de una expansión masiva del programa de Escuela Nueva. Por lo tanto, se realizó en 1987 una nueva evaluación cuando ya había unas 8.000 escuelas trabajando con el método de la Escuela Nueva.

La evaluación de una muestra aleatoria de las escuelas multigrados de 1987 mostró que las escuelas unitarias que operaban con el método Escuela Nueva obtenían un menor porcentaje de repitentes que las escuelas que tenían una maestra por curso (47.2 $\mathrm{v} / \mathrm{s} 53.9 \%$ ). El bajo nivel de repetición, era en realidad, más significativo dado que las que operaban con Escuela Nueva habían sido capaces de reducir la deserción con respecto a la escuela tradicional (Tabla No. 4), en la medida que la evidencia sugiere que los alumnos con riesgo de deserción suelen tener más altas tasas de repetición. Aunque la deserción en el primer grado es algo más alta en Escuela Nueva que en las escuelas graduadas (grado en el cual la metodología es similar en los dos tipos de escuelas ya que está centrada en el aprendizaje de la lectura), en los otros grados es mucho más baja en Escuela Nueva que en las escuelas graduadas y el método de la Escuela Nueva es, incluso, capaz de recuperar a algunos alumnos en el quinto grado (hay más alumnos de quinto grado inscritos en Escuela Nueva al final que al comienzo del año escolar). Pero estos resultados positivos deben ser controlados por el nivel de rendimiento, porque la repetición se puede reducir bajando estándares o elevando el nivel de aprendizaje. Es por esto que se deben comparar los puntajes en pruebas estandarizadas del rendimiento académico.

Tabla 4

Colombia: repetición y deserción (1987)

\begin{tabular}{lcc} 
Indicador & $\begin{array}{c}\text { Escuela } \\
\text { Nueva }\end{array}$ & $\begin{array}{c}\text { Escuela Graduados } \\
\text { Rural }\end{array}$ \\
\hline Repetición & $47.2 \%$ & $53.9 \%$ \\
Deserción grado 1 & $10.5 \%$ & $8.6 \%$ \\
Deserción grado 2 & $5.1 \%$ & $9.3 \%$ \\
Deserción grado 3 & $2.9 \%$ & $7.8 \%$ \\
Deserción grado 4 & $0.7 \%$ & $7.9 \%$ \\
Deserción grado 5 & $-3.0 \%$ & $11.1 \%$
\end{tabular}

Fuente: C. Rojas and Z. Castillo, Instituto Ser, 1988.

En pruebas administradas en 1987 para medir el comportamiento cívico-social; autoestima; matemáticas para tercero básico y castellano para tercer y quinto grados (temas seleccionados para la evaluación) los niños de cursos multigrados de Escuela

100 José Rodríguez, El logro en matemáticas y lenguaje en la educación primaria en Colombia, Instituto SER de Investigaciones, Bogotá, 1978 pp. 267-268. C. Rojas y Z. Castillo, Evaluación del programa Escuela Nueva en Colombia, Instituto SER de Investigaciones, Bogotá, 1988. 
Nueva tuvieron un puntaje bastante más alto que aquellos que asistían a escuelas graduadas (tradicionales) rurales (Tabla No. 5). Por lo tanto, la reducción en la repetición fue el resultado de un mayor rendimiento y no de más bajos estándares. Al revés, se subieron los estándares, es decir, la repetición habría sido menor al mantener los estándares tradicionales. El análisis de la autoestima demostró que los niños que están en el programa de Escuela Nueva tienen una mayor autoestima que los que asisten a escuelas rurales graduadas. El hecho de que en Escuela Nueva la autoestima de las niñas sea similar a la de los niños es particularmente importante, puesto que demuestra los efectos equitativos de una metodología de mayor participación.

\section{Tabla 5}

Colombia: comparación de los puntajes de alumnos de EN y de escuelas tradicionales en ocho áreas

\begin{tabular}{|c|c|c|c|c|c|c|c|c|}
\hline & & \multicolumn{3}{|c|}{ Escuela Nueva } & \multicolumn{3}{|c|}{ Escuela Tradicional } & \multirow[b]{2}{*}{$\%$} \\
\hline & Grado & No. & Pun & aje & No. & Pur & aje & \\
\hline Matemáticas & 3ro. & 1143 & 15.3 & 7.3 & 681 & 13.7 & 6.7 & $11.7^{*}$ \\
\hline Español & 3ro. & 1143 & 13.8 & 5.2 & 684 & 11.6 & 5.4 & $19.0^{*}$ \\
\hline Matemáticas & 5to. & 743 & 13.9 & 6.2 & 516 & 14.0 & 6.2 & -0.7 \\
\hline $\begin{array}{l}\text { Español } \\
\text { Autoconcepto }\end{array}$ & 5to. & 744 & 15.4 & 5.1 & 510 & 14.2 & 5.1 & \\
\hline $\begin{array}{l}\text { Académico } \\
\text { Autoconcepto }\end{array}$ & Todos & 1840 & 36.1 & 5.4 & 1166 & 35.8 & 5.5 & 0.8 \\
\hline $\begin{array}{l}\text { Social } \\
\text { Actitud }\end{array}$ & Todos & 1850 & 33.1 & 4.8 & 1176 & 32.4 & 5.0 & $2.2^{*}$ \\
\hline $\begin{array}{l}\text { Socio/cívica } \\
\text { Actitud }\end{array}$ & 10. & 1060 & 13.2 & 3.1 & 587 & 12.4 & 3.2 & $6.5^{*}$ \\
\hline Socio/cívica & 3ro. & 735 & 15.4 & 2.7 & 466 & 14.8 & 2.5 & $4.1^{*}$ \\
\hline
\end{tabular}

$\left(^{*}\right) \quad$ Estadísticamente significativo al 5\% (o menos)

Fuente: C. Rojas y Z. Castillo, Instituto SER de Investigación, 1988. pp. $139,142,148,152,156,158$ y 161.

En resumen, al completar su expansión masiva la Escuela Nueva muestra ser más eficiente (menor repetición y deserción) y, al mismo tiempo, haber elevado los niveles de rendimiento de los alumnos. La repetición es todavía un problema importante y deberían ser investigados los efectos que tienen en ella el ausentismo estacional, el elevar los estándares y otros factores (incluyendo la tradición de hacer repetir a muchos alumnos). En todo, caso el repetir cuando se usa un modelo de aprendizaje para el dominio es bastante más racional que hacerlo como resultado fracasar con el modelo de enseñanza tradicional frontal.

\section{Juicios subjetivos con respecto al programa Escuela Nueva}

Los juicios de los profesores que participan en el programa de Escuela Nueva y de los especialistas que han visitado Escuela Nueva también son positivos y el entusiasmo de los estudiantes de Escuela Nueva es en sí otra manera de apreciar su éxito. La evaluación de las escuelas realizada en 1987 por el Instituto SER detectó que un 89.3\% de los maestros creían que Escuela Nueva era mucho mejor que las escuelas típicas y la opinión de las autoridades locales fue similar. Los maestros también valoraron positivamente cada uno de los elementos usados por la Escuela Nueva (Tabla No 6). Los 
textos de autoaprendizaje también tuvieron gran aceptación entre los maestros (Tabla No 7).

\section{Tabla 6}

Colombia: evaluación de los maestros de los principales elementos que usa EN en sus situaciones de aprendizaje

\begin{tabular}{llllccc}
\multicolumn{5}{c}{ Importancia asignada al factor (\% de los maestros) } \\
& $\begin{array}{l}\text { Muy } \\
\text { Factor Calificado }\end{array}$ & Alta & Aceptable & Alguna & Nada \\
& Alta & & & & \\
Textos de aprendizaje & 89.2 & 10.8 & - & - & - \\
Biblioteca & 81.5 & 16.1 & 1.8 & 0.6 & - \\
Rincones de aprendizaje & 76.2 & 23.2 & 0.6 & - & - \\
Mapa de la escuela & 66.1 & 33.3 & 0.6 & - & - \\
Afiches producidos & 60.2 & 39.2 & 0.6 & - & - \\
Monografía de la comunidad & 49.4 & 44.6 & 4.8 & 1.2 & - \\
Diario del alumno & 55.8 & 29.1 & 6.0 & 7.3 & 1.8 \\
Calendario actividad agrícola & 26.7 & 51.5 & 9.7 & 7.3 & 4.8 \\
Ficha de la familia & 44.3 & 46.7 & 5.4 & 3.6 & - \\
Buzón de sugerencias & 42.5 & 44.9 & 8.4 & 3.6 & 0.6 \\
Libro de concurso & 41.8 & 40.6 & 10.3 & 5.5 & 1.8
\end{tabular}

Fuente: C. Rojas y Z. Castillo, Instituto SER, 1988, p. 120.

Tabla 7

Colombia: evaluación de los maestros de la calidad de los textos de autoaprendizaje

Grado de acuerdo con afirmación (\% de maestros)

$\begin{array}{lccccc}\text { Afirmación que califican } & \text { Muy } & \text { Alta } & \text { Algo } & \text { Poco } & \text { Nada } \\ & \text { Alta } & & & & \\ \text { Fácil de comprender } & 30.5 & 49.1 & 18.0 & 1.8 & 0.6 \\ \text { Diseño, letra, gráficos } & 43.4 & 44.0 & 9.0 & 3.0 & 0.6 \\ \text { Actividades pertinentes } & 37.7 & 49.1 & 10.8 & 2.4 & - \\ \text { Buena actividad práctica } & 34.7 & 44.9 & 16.8 & 3.6 & - \\ \text { Trabajo para casa es adecuado } & 18.6 & 39.5 & 29.3 & 12.0 & 0.6 \\ \text { Buena actividad de recuperación } & 23.2 & 46.3 & 22.6 & 6.1 & 1.8 \\ \text { Faltan temas importantes } & 39.2 & 27.7 & 15.1 & 10.2 & 7.8\end{array}$

Fuente: C. Rojas y Z. Castillo, Instituto SER, 1988, p. 120.

Un gran número de especialistas que ha visitado Escuela Nueva ha hecho también evaluaciones positivas. Por ejemplo, todos los participantes del Encuentro de Especialistas en Investigación que se desarrolló en Bogotá, mayo 1987 que visitaron algunas de las escuelas del Programa Escuela Nueva manifestaron que esas escuelas estaban ofreciendo una educación de alta calidad. Lo mismo ocurrió con los participantes en el Encuentro de especialistas en Educación Pre-escolar realizado en Paipa en 1988 y una docena de chilenos especialistas en currículo que visitaron escuelas que aplicaban el modelo Escuela Nueva a mediados de los 80 y principios de los 90.

Una misión de la Unesco, que visitó Colombia, en 1985 informó: "de la evaluación de los materiales utilizados por el profesor y de las observaciones de visitas a las salas, la 
misión puede señalar claramente que los resultados son de un alto nivel en términos absolutos y constituyen una experiencia de indudable valor internacional". Organizaciones no gubernamentales como "Save the children" y Unicef están promoviendo la introducción de las estrategias usadas por Escuela Nueva en otros países de América Latina y el Caribe. Finalmente, se puede mencionar que el Banco Mundial seleccionó a Escuela Nueva como una de las tres mejores experiencias en educación primaria, por lo que está llevando a cabo una cuidadosa evaluación que incluye una detallada investigación de campo que será publicada en 1992.

\section{Es factible ofrecer una buena calidad de la educación, pese a los recursos limitados}

Escuela Nueva ha mostrado que los países pueden obtener mejor educación por cada dólar, pero para hacerlo Escuela Nueva ha usado los recursos de una manera diferente y en muchos países puede ser difícil el reasignar recursos. Los planificadores que busquen la posibilidad de introducir innovaciones deben tener en cuenta que: se deben cambiar los textos (esto no ofrece grandes problemas porque los textos son reemplazados o publicados nuevamente cada año o, por lo menos, cada dos o tres años); los profesores deben usar su tiempo de una manera diferente; el entrenamiento de los profesores se debe llevar a cabo de una manera diferente y los padres deben estar dispuestos a aceptar nuevos métodos de enseñanza para sus hijos. Por otra parte, ahora que la Escuela Nueva se ha puesto en práctica con éxito en Colombia la sociedad está más dispuesta para dar más dinero para la educación. Además de dar una mejor calidad, Escuela Nueva ha ayudado a implementar políticas que no implican mayores costos tales como: que las escuelas multigrados ofrezcan todos los grados; capacitar a los maestros en microcentros; eliminar el trabajo de preparar clases; incrementar la capacidad local para solucionar problemas; mejorar el diseño de los textos $\mathrm{y}$, con algún pequeño costo adicional, su disponibilidad; aprovechar las mejores escuelas que existen en cada área; usar a los padres para llevar a cabo trabajos y asociarlos en labores escolares; y usar los recursos locales para enriquecer el aprendizaje.

En resumen, basados en investigaciones y en el desarrollo de experiencias Escuela Nueva mostró su existencia y logró reconocimiento en la esfera nacional. Luego, mediante una mezcla de propaganda, apoyo estratégico, prestigio académico del grupo promotor y simple buena suerte logró ofrecer una cobertura nacional en el área rural y luego gradualmente ha comenzado a ser implementada en escuelas primarias graduadas urbano-marginales. Ahora busca reconocimiento en el plano internacional y la pregunta es si Escuela Nueva constituye realmente uno de los modelos que permitiría resolver los problemas detectados en América Latina y que ya han sido descritos anteriormente en la Parte 1. Tomará algún tiempo tener un veredicto. Por mientras, las condiciones para llevar a cabo innovaciones similares se comentan en el próximo capitulo para aquellos que estén interesados en elevar la calidad de la educación de países en vías de desarrollo.

\section{Condiciones para replicar la experiencia}

La experiencia obtenida en la media docena de países que han tratado de implementar adaptaciones del modelo de Escuela Nueva y las innovaciones que han fallado al tratar de masificarse ${ }^{101}$ muestran que al adaptar Escuela Nueva, como con cualquier otro tipo de innovación, se tienen que tomar en cuenta ciertos aspectos claves de la gestión del

\footnotetext{
${ }^{101}$ Por ejemplo, Elizardo Pérez y la experiencia de Warisata en Bolivia; la colonización San Lorenzo en Piura, Perú; Cardozo y la Escuela Activa en Paraguay; Carlos Vergara en Argentina; Varela y la escuela activa en Uruguay; las Consolidadas y el Plan Victoria en Chile; y las múltiples experiencias de sistemas "nuclear' en la zona rural.
} 
proceso (muchos de los cuales no son educativos). Es imposible presentar en este trabajo un análisis detallado de cómo introducir satisfactoriamente innovaciones educativas, pero al menos hay siete aspectos, que se dan a conocer en esta sección, que conviene tener presentes: (i) vender la innovación en términos de los resultados probables; (ii) respaldar la innovación por un sólido consenso social, dado el largo tiempo que se requiere para que madure una innovación educativa; (iii) identificar a los posibles aliados y opositores y dedicar tiempo a ganar el apoyo de estos últimos; (iv) los planificadores deben estar listos para transformar el consenso social en un flujo constante de recursos que permitan continuar la experiencia; (v) identificar los aspectos claves que puedan limitar la implementación de otros aspectos de la innovación; (vi) adaptar la innovación al contexto local, pero proteger los elementos básicos del modelo de la innovación y (vii) asegurar la constante adaptación y acumulación del conocimiento educativo.

\section{La innovación debe ser promovida en términos de los impactos probables}

El grupo que desee implementar una innovación debe identificar los subproductos de la innovación y los efectos indirectos (spill-over) si quiere "vender" la innovación (y lograr el financiamiento necesario) a los que toman decisiones. Por ejemplo, en el caso de innovaciones similares a las de la Escuela Nueva se debería comentar su efecto en la formación de la futura fuerza de trabajo ya que se ajusta a los requerimientos para participar en los "círculos de calidad" y al trabajo en equipo. El desarrollar la habilidad para "aprender haciendo" y para entender las instrucciones escritas elevará dramáticamente la capacidad de la mano de obra no calificada. Aunque estos posibles impactos de la Escuela Nueva no se han evaluado, el analfabetismo funcional es un importante reto en los países de América Latina y EN permite enfrentarlo con seriedad.

\section{La innovación es un asunto de largo plazo y necesita de un consenso social}

No hay formas milagrosas para tener una educación de calidad. Los maestros deben ver y ensayar el "verdadero modelo" en buenas escuelas de demostración en vez de obtener explicaciones verbales de segunda o tercera mano de qué es lo que se debería hacer para poner a operar un nuevo modelo educativo. Esto es un obstáculo serio, porque desarrollar escuelas de demostración toma, por lo menos, dos o tres años para madurar, pero los ministros de Educación sólo pasan un año o un año y medio en su puesto. (Hubo seis ministros de Educación en Colombia durante el período 1982 - 1990). Es por esto, que una expansión masiva de un modelo debe tener una cierta garantía de poder ser probada durante, al menos cuatro años, de manera que llegue a tener la fuerza suficiente (si logra triunfar) como para luego continuar, a pesar de los continuos cambios ministeriales. El consenso social, expresado en un acuerdo público, una ley, un contrato con una agencia internacional o el carisma de un educador o estadista son mecanismos alternativos para mantener el financiamiento y el apoyo político durante todo el período de desarrollo inicial. La necesidad del consenso fue reconocida por los ministros de Educación en la reunión realizada en Quito en 1991.

\section{Hay que prever los impactos en los especialistas, funcionarios y maestros}

El grupo de innovadores tiene que estimar las posibles reacciones a las innovaciones. Mientras los maestros pueden apoyar las innovaciones porque pueden enseñar mejor, los expertos en currículo podrían criticar las innovaciones en términos de situaciones ideales y utópicas en vez de comentar los beneficios con respecto de las prácticas presentes. Los innovadores y planificadores deben encontrar las estrategias adecuadas para romper las oposiciones iniciales y generar un ciclo positivo. El enseñar mediante el 
"redescubrimiento" (Enfoque Científico) y el incrementar la autoestima en la escuela primaria podría crear un ciclo positivo que mejore el prestigio social de la educación. Los maestros que trabajan con niños que están observando, describiendo, comparando y evaluando eventualmente usarán los mismos enfoques al diseñar sus propias experiencias de aprendizaje. Más aun, una mayor confianza en los métodos de enseñanza y mayores logros de los alumnos aumentarán, probablemente, el interés en una mayor experimentación. Así, el traer un enfoque científico y un nuevo entusiasmo en la educación podría generar la misma revolución que la ciencia ha causado en la Medicina e, incluso, salarios relativamente mejores para los maestros. Mejores alumnos podrían estar interesados en llegar a ser educadores y, así, iniciar un "círculo virtuoso" que ahora parece imposible.

\section{Lograr un continuo flujo de recursos complementarios para el éxito}

Se deben alterar muchos elementos, en el tiempo preciso, para crear el cambio deseado. Para orquestar los diversos elementos se requiere un buen gerente (el grupo promotor en el caso de Colombia) que esté preocupado de todas las concertaciones y programaciones necesarias. Algunos elementos, tales como la propaganda y el invitar a los ministros recién nombrados podrían ser tan importantes como las sillas, los bancos y los textos de autoaprendizaje. El mantener el avance y la aceptación de la experiencia puede ser indispensable para que tenga éxito. Es fácil mantener un programa en movimiento cuando el éxito genera más éxito. Pero el fallar en un paso crucial podría ser el fin del mejor esfuerzo previo. Se requiere talento administrativo para continuar a nivel masivo; no basta tener el programa a cargo de un educador por bueno que sea. Si el educador no tiene entrenamiento en administración se debe obtener la ayuda de expertos en administración.

\section{Asegurar que los textos de autoaprendizaje cumplan con ciertos estándares de calidad}

Para mejorar la calidad de la educación hay que identificar los aspectos claves que podrían limitar la implementación de la innovación. Si la calidad de la educación se busca mediante una educación activa entonces los textos prototipos deberían cumplir con un elevado estándar de calidad. Los textos de autoaprendizaje son diferentes de los textos tradicionales y, por eso, serán atacados por los autodenominados expertos en diseño curricular o especialistas en disciplinas, escritura, diseño gráfico o evaluación. Suele ser difícil presentar los textos en un lenguaje sencillo (aun al costo de alguna precisión en términos de la disciplina) que pueda ser comprendido por el lector. Cada corrección al texto tiende a aumentar la cantidad de páginas en vez de mantenerlo simple y breve. Estos son peligros que los planificadores deben tratar de eliminar a través de la persuasión y compromisos. El usar criterios claros de calidad para evaluar los textos puede reducir los riesgos de fracaso de la innovación ${ }^{102}$.

\section{Ajustando el "kit" (o modelo) al contexto local}

Mientras el modelo (teoría) para la innovación debiera ser el mismo en cualquier aplicación, los elementos, el tiempo empleado, los ejemplos y el contenido del currículo podría diferir ampliamente entre una y otra aplicación. El peligro está en ir demasiado lejos en las adaptaciones y, de paso, distorsionar los elementos claves del modelo. Por ejemplo, los textos adaptados para la experiencia en Bolivia introdujeron la secuencia de tópicos y contenidos descritos en el currículo nacional. Sin embargo, al llevar a cabo esos cambios también se dejó de lado el dar instrucciones para: observar, describir, escribir,

\footnotetext{
${ }^{102}$ Schiefelbein y Farrés, "Evaluación...", Op. cit. E. Schiefelbein, "Criterios para evaluar propuestas de cambio cunicular en educación básica", Estudios Pedagógicos, No. 16, 1990. pp. 107-115. 
discutir en grupos, auto-evaluar, mejorar el producto de la experiencia y, finalmente, presentar el trabajo final para que el maestro realice una evaluación formativa/sumativa final. En resumen, la adaptación también debería someterse a un proceso de evaluación la versión final contra el criterio clave del modelo (tal como la retraducción cuando se traducen cuestionarios a otro idioma).

La supervisión y el replanteamiento son necesarios durante todo el proceso. Por ejemplo, las estrategias para implementar una innovación probablemente se ven afectadas por las brechas (gaps) y los errores. Tal como se comentó en la segunda parte los calendarios planificados (para los seminarios de entrenamiento, el trabajo de los maestros con la comunidad y la distribución de los textos y materiales de autoaprendizaje) podrían ser muy diferentes de la realidad. Diseñar la experiencia requiere de una cuota de creatividad y artesanía, pero un seguimiento muy de cerca del proceso es la verdadera condición para replicar en buena forma la Escuela Nueva o cualquiera otra innovación similar.

\section{Adaptar compartir y acumular conocimientos educativos}

Las técnicas de educación se deben adaptar a las condiciones locales específicas, pero hay que evitar partir de "cero". Pero para llevar a cabo una continua adaptación tienen que participar aquellos que están en la frontera del arte de enseñar. Para entregar esas técnicas de vanguardia a todos los demás maestros, hay que preparar materiales los alumnos puedan usar directamente y que requieran pocas instrucciones para los maestros (y evaluarlos antes de entregárselos a los maestros). Equipos flexibles que combinen los talentos de las universidades y de las escuelas para desarrollar modelos y materiales (como los de Escuela Nueva) parecen ser de gran valor en estos procesos de adaptación. Se pueden usar equipos similares para implementar las innovaciones, aunque hay múltiples formas de organizar las experiencias y responsabilidades del personal de escuelas y universidades ${ }^{103}$. Los profesores de las facultades universitarias tienen mayor autonomía que los maestros de las escuelas públicas. Ellos pueden ayudar para que los maestros de escuela exploren las fronteras del conocimiento de la pedagogía.

Tales equipos de diseño/asesoría deben estar disponibles en todas las etapas del proceso de implementación. Por ejemplo, Escuela Nueva concebía inicialmente la supervisión como un proceso de seguimiento para los profesores entrenados para operar en el programa de Escuela Nueva. Sin embargo, cuando se masificó la experiencia al nivel nacional el grupo promotor transformó la supervisión de las escuelas en la animación de una reunión mensual no formal de unos doce maestros en una escuela de demostración u otro lugar apropiado (talleres o microcentros). Siempre va a haber incidentes y cambios en la introducción gradual de la innovación y los planificadores deberían estar preparados para detectarlos a tiempo.

\section{Conclusiones y nuevos desafíos}

La evidencia revisada hasta aquí sugiere tres conclusiones y un número similar de nuevos desafíos. Las conclusiones se refieren a la necesidad de elevar la calidad de la educación, la factibilidad de implementar innovaciones a escala nacional y a las políticas complementarias que se pueden ensayar cuando los profesores actúan como acompañantes y animadores en vez de "transmisores". Los desafíos tienen relación con las próximas etapas del desarrollo del modelo de Escuela Nueva, el impacto de la

\footnotetext{
${ }^{103}$ Glen Irvin, "Collaborative Teacher Education", Kappam, Vol. 71, No. 8, abril de 1990. p. 623.
} 
investigación relacionada con la calidad y con el nivel (pre-escolar o educación secundaria) al cual debería extenderse Escuela Nueva. Estas conclusiones y desafíos se comentan en el resto de este capitulo.

\section{Existe urgencia para mejorar la educación básica}

Aun si se rechaza el modelo de la Escuela Nueva de Colombia se mantiene vigente la urgencia para cambiar la "escuela típica" a fin de elevar la calidad educativa de los niños que provienen de familias de niveles socioeconómicos bajos. Una y otra vez es posible revisar los principios educativos que ya están disponibles para que líderes carismáticos los combinen de diferentes maneras. Mientras tanto, a menos que sudan otras alternativas, la Escuela Nueva constituye un buen modelo que se puede usar junto con otras estrategias para enfrentar los problemas de baja calidad y malos rendimientos que afectan especialmente a los alumnos provenientes de contextos socio-económicos bajos. Es una experiencia que merece ser adaptada y probada en otros países.

\section{Tanto el experimento como la masificación de Escuela Nueva son factibles y eficientes}

Al implementar una adaptación de Escuela Nueva en un nuevo país no se tiene que seguir el desarrollo histórico que tuvo la experiencia de Colombia (la inversión inicial ya se realizó). Pero es bueno estar consciente de los procedimientos y costos a través de los cuales Escuela Nueva elevó la calidad de las escuelas rurales públicas en un país de América Latina. Como un proyecto local cuidadosamente implementado (ayudado por la casualidad que permitió a un grupo trabajar como equipo durante 15 años), logró generar un nuevo sistema de ofrecer educación (los problemas enfrentados en Colombia y la manera en que fueron solucionados están comentados en el capítulo 6). Aunque el proceso es demasiado complejo para ser analizado en detalle hay que destacar, por lo menos, cuatro aspectos de ese desarrollo: (i) La Escuela Nueva fue capaz de cambiar gradualmente la asignación de los recursos usados en el sistema nacional de educación primaria, (ii) la Escuela Nueva tuvo éxito para ampliarse a nivel nacional al definir elementos estándares que los maestros podían usar luego de observar a los maestros de una escuela de demostración de bajo costo, (iii) la Escuela Nueva estuvo protegida por funcionarios visionarios del Ministerio de Educación y por especialistas de organizaciones internacionales que estaban convencidos de la excelencia del modelo y (iv) el grupo promotor fue capaz de integrar a especialistas y educadores de diferentes grupos de presión en la evaluación y refinamiento de un modelo que siempre ha estado (aún hoy día) en el proceso de ser revisado y ajustado.

\section{Una innovación exitosa puede facilitar la aplicación de políticas complementarias}

Es posible implementar otras macro-estrategias alternativas para elevar la calidad educativa una vez que se ha puesto en práctica el modelo Escuela Nueva. Por ejemplo, el énfasis en lectura/escritura durante los dos primeros grados se puede complementar con el "grado cero" para asegurar que haya mayor tiempo para que los niños desarrollen sus condiciones previas (aprestamiento) para leer. También es posible ofrecer educación intercultural bilingüe. Además, es también oportuno empezar a pensar la manera de relacionar un experimento como Escuela Nueva con la implementación de los sueños de los especialistas en informática. Algunos intentos sugieren que la informática debe ser incluida como una herramienta poderosa para llevar a cabo innovaciones capaces de elevar la calidad de la educación. Por ejemplo, el sistema Degem usado en Israel, facilita la evaluación diagnóstica y los Sistemas Instruccionales Integrados (IIS), recientemente 
implementados en Estados Unidos ${ }^{104}$ o la experiencia que está siendo llevada a cabo en Costa Rica ofrecen nuevas formas de enseñanza. Este no es el lugar para desarrollar el tema, pero por lo menos se puede recordar a los educadores la necesidad de asegurar que las innovaciones que se propongan sean compatibles (eventualmente) con los probables desarrollos que pueda alcanzar la informática en el futuro cercano.

\section{¿Cuál es la próxima etapa de Escuela Nueva?}

La educación es un proceso de nunca acabar, pero los planificadores deben estar preparados para enfrentar ese futuro incierto. Por eso es que la principal pregunta en relación con Escuela Nueva también es: ¿qué sigue? Los textos de autoaprendizaje pueden ser mejorados, tanto en su diseño, como en contenido e impresión. El mejoramiento de los textos se puede medir en términos de los criterios que deben satisfacer, los que aproximadamente se tienden a definir con una precisión creciente ${ }^{105}$. El modelo puede llegar a ser aún más consistente, dado que la teoría que hay detrás del programa de Escuela Nueva se está explicitando y los elementos pueden evolucionar o cambiar $^{106}$. Los elementos claves del modelo se pueden llegar a identificar con más facilidad, ahora que es posible disponer de videos del proceso escolar, aun cuando los modelos puedan ser mejorados en el futuro próximo. Es posible introducir más modelos de aprendizaje como parte de la metodología de Escuela Nueva ${ }^{107}$ y muy pronto los computadores estarán disponibles en todas las escuelas ${ }^{108}$.

¿Cómo se elevará la calidad educativa gracias a las nuevas investigaciones, la medición de la calidad y la informática?

Dos áreas de lo experimentado en Escuela Nueva requieren investigaciones adicionales: escritura y evaluación. La investigación en escritura ha empezado a examinar en qué condiciones los estudiantes aprenden a escribir, incluyendo los procesos de razonamiento que acompañan la generación y reformulación de ideas que permiten a los alumnos entender y recordar el material que leen. El resultado de la investigación en esta área debería mejorar la habilidad de los niños para leer, sobre la cual el modelo de la Escuela Nueva (y probablemente cualquier innovación pertinente) está construido. Por el momento, los profesores del primer grado enfrentan un alto grado de heterogeneidad en sus salas, pero debería investigarse para definir con más precisión cuáles niños deben tener un tratamiento instructivo ad-hoc ${ }^{109}$.

Deberían crearse pruebas de rendimiento de manera que si las escuelas enseñan para el test, estén enseñando lo que la sociedad cree que los alumnos debieran saber ${ }^{110}$. Al

${ }^{104}$ M. Sherry,"Implementing an integrated instructional system: critical issues", Kappan. Vol. 72. No. 2, octubre de 1990, pp. 118-120.

${ }^{105}$ E. Schiefelbein, "Criterios para evaluar propuestas de cambio curricular en educación básica", Estudios Pedagógicos. No. 16, Universidad Austral, Valdivia. 1990.

106 E. Schiefelbein, "Redefining basic education for Latin America - Lessons to be learned from the Colombian Escuela Nueva", Fundamentals of Educatíonal Planning Series, IIEP, Paris, 1992.

${ }_{107}$ Existe media docena de otros modelos que podrían ser integrados. Ver K. H. Flechsig and E. Schiefelbein, op cit.

${ }_{108} 40 \%$ de los alumnos de Costa Rica practicaba en 1990 durante una o dos horas por semana en computadores personales.

109 D. Speece y D. Cooper, "Ontogeny of school failure: classification of first grade children", American Educationaí Research Journal, Vol. 27, No. 1, primavera dc 1990, pp. 119-140. AA. Reynolds, "Early schooling of children at risk", American Educational Research Journah Vol. 28, No. 2, verano de 1991. pp. 392-422. C. Goldenberg y R. Gallimore, 'Local knowledge, research knowledge and educational change'. Educational Researcher Vol. 20, No. 8, noviembre de 1991, pp. 2-14.

110 John Goodlad, Teachers of our nation's schools, Jossey-Bass, 1990. 
crear tests de rendimiento que se acerquen al criterio de comprensión conceptual de los alumnos (fidelidad cognitiva del test) y al de habilidad para aplicar sus conocimientos a situaciones nuevas (pertinencia en procesos del test) las escuelas tendrán herramientas para medir los avances y beneficiar - más que crear caos - en nuestro sistema de educación $^{111}$. Eventualmente, las escuelas estarán provistas con pruebas adaptables a computadores en las que la respuesta de un alumno en un ítem determinará el próximo ítem que se le presente en la pantalla. En caso de problemas un módulo de diagnóstico examinará qué tipo de habilidades parecerían faltarle a ese alumno. Los resultados se mostrarán en la pantalla al final del test y generará un diagnóstico que solo el maestro podrá ver. La prueba determinará el tipo de error que comete el alumno. Sin embargo, a pesar del valor que tengan estas pruebas, es probable que revelen poco de los alumnos y que el maestro tenga, finalmente, que confiar en su juicio profesional ${ }^{112}$.

\section{¿El próximo paso para Escuela Nueva: educación pre-escolar o educación secundaria?}

¿Debería expandirse el modelo de la Escuela Nueva a la estimulación temprana y a la educación inicial o continuar en la educación secundaria? Existe una conexión natural entre el enfoque de Escuela Nueva y el del currículo cognitivo, (High Scope), peto los altos costos en términos de atender pocos alumnos por parvularia y el alto costo de los materiales hacen difícil implementar la extensión hacia abajo en países en vías de desarrollo. En todo caso, es necesario combinar Escuela Nueva con algún tipo de programa pre-escolar y kindergarden para prevenir los problemas de aprendizaje. La investigación disponible sugiere que la estimulación temprana puede prevenir problemas de aprendizaje y costosos tratamientos remediales ${ }^{113}$.

Los graduados de la Escuela Nueva están recién comenzando a inundar las escuelas secundarias colombianas. Algunas escuelas secundarias experimentales están avanzando con éxito, pero es demasiado temprano para predecir resultados. Existen, también, combinaciones del enfoque de la Escuela Nueva con otros experimentos de gran interés ${ }^{114}$.

Los resultados de las evaluaciones que estarán listas a mediados de esta década ayudarán a decidir cuál es la mejor forma de continuar la experiencia de Escuela Nueva.

\footnotetext{
${ }^{111}$ R.J. Shavelson, N.B. Carey y N.M. Webb, "Indicators of science achievement: options for a powerful policy instrument", Kappan, Vol. 71, No. 9, mayo de 1990, pp. 692-697.

112 Willard Duckett, "When Average isn't good enough" [An interview with doy Frechtling], Kappan, Vol. 71, No. 8. abril, 1990, p. 640.

${ }_{113}$ Robert G. Myers, The twelve who survive, Routledge, London (forthcoming).

114 F. Arbad, E. Gutiérrez y F. de Valcárcel. "El sistema de aprendizaje tutorial de FUNDAEC: SAT", CELATERR-FUNDAEC, Cali, agosto, 1988, pp. 26. Ana Lía de Longhi y Carmen Peme de Arenega, Una introducción al método científico a través de la educación ambiental, Universidad de Córdoba, 1990.
} 